\title{
The Long Road to Health: Healthcare Utilization Impacts of a Road Pavement Policy in Rural India *
}

\author{
Shilpa Aggarwal ${ }^{\dagger}$
}

December 10, 2018

\begin{abstract}
Despite demand-stimulation efforts, coverage rates of many essential health services remain low in developing countries, suggesting that there may be binding supply constraints, such as poor access. This paper utilizes quasi-random variations in roadpavement intensity to study the impact of improved access on adoption of reproductive health services. I find that road construction led to higher rates of institutional antenatal-care and deliveries, which translated into better medical care and vaccination coverage. Most gains accrue from repeat visits by existing patients, and some from new entrants into the formal health sector. Evidence suggests that beneficiaries travel farther to see better providers.
\end{abstract}

Keywords: Roads, Healthcare, Service Delivery, Vaccination

JEL Classification: I15, I18, O12, O18

*I thank Pia Basurto, George Bulman, Rossella Calvi, Ujjayant Chakravorty, Ritam Chaurey, Sisir Debnath, Sarang Deo, Carlos Dobkin, Tarun Jain, Karthik Muralidharan, Jennifer Poole, Jonathan Robinson, Sheetal Sekhri, Nirvikar Singh, Vishal Singhal, Alan Spearot, and Sujata Visaria for their feedback at different stages of this project. I also benefited greatly from comments provided by seminar audiences at IIM Bangalore, Indian School of Business, and UC Santa Cruz. Ishani Chatterjee provided excellent research assistance. I thank the Indian Institute of Population Studies for access to the DLHS data, and S Anukriti and Nishith Prakash for useful pointers about the data. All errors are my own. An older version of this paper was the second chapter of my dissertation at UC Santa Cruz.

${ }^{\dagger}$ Indian School of Business, Hyderabad, India, email: shilpa_aggarwal@isb.edu 


\section{Introduction}

Despite their proven efficacy in arresting maternal and child morbidity and mortality, coverage rates of simple preventive measures, such as medically-supervised deliveries for women and adherence to the recommended vaccination protocols for children, remain low in several developing countries. The WHO reports that over the period 2003-2013, less than half of all pregnant women in low-income countries received the recommended number of antenatal care visits (i.e., 4 visits) and just over half delivered in the presence of a skilled medical attendant (WHO, 2015) 1 Consequently, every year, more than a quarter of a million women die due to complications related to pregnancy and childbirth, and approximately 4 million babies do not survive up till their first birthday, a vast majority of both due to entirely preventable causes (UNICEF, 2018; WHO, 2015).

Recognizing this, policy-makers have prioritized improving coverage of reproductive and child health interventions ${ }^{2}$ Simultaneously, a complementary academic literature has tried to understand the drivers of demand for preventive health products and services (including, but not limited to, those meant for mothers and young children) - for example, free or subsidized provision (Cohen and Dupas, 2010; Meredith et al., 2013; Okeke et al., 2013; Dupas, 2014; Okeke et al., 2016); provision on credit (Tarozzi et al., 2013; Guiteras et al., 2016); liquidity improvements through savings (Dupas and Robinson, 2013), or through unconditional cash transfers (Paxson and Schady, 2010; Robertson et al., 2013); conditional cash or in-kind incentives (Morris et al., 2004; Lagarde et al., 2007; Banerjee et al., 2010; Debnath, 2014)3; information provision (Jalan and Somanathan, 2008; Ashraf et al., 2013; Dammert et al., 2014; Godlonton et al., 2016); pre-commitment (Gine et al., 2010; Schilbach, 2015); and social learning and peer effects (Banerjee et al., 2007; Brunson, 2013; Adhvaryu, 2014 ).4

In contrast, supply-side constraints to improved coverage have received much less attention in the academic literature, despite evidence of widely prevalent bottlenecks.5 Notably, primary health facilities, especially those in rural areas of developing countries, are often few and far between $\sqrt[6]{6}$ making access difficult for the average patient, and potentially driving

\footnotetext{
${ }^{1}$ These are country-wide averages, with wide heterogeneity in coverage by economic and educational status. For instance, the median proportion of skilled-attendant deliveries was $34 \%$ in the poorest quintile and $89 \%$ in the richest.

${ }^{2}$ For instance, the Millennium Development Goals sought to reduce the under-5 mortality rate by twothirds and the maternal mortality rate by three-fourths between the years 1990 and 2015 .

${ }^{3}$ The literature on conditional incentives is large and growing. See Palmer et al. (2004) for a review of older studies on this topic.

${ }^{4}$ See Dupas (2011) for a review of this literature.

${ }^{5}$ For instance, shortages and stock-outs of essential health goods like condoms, anti-malarials, and medicines to treat diarrhea and pneumonia are frequent, rendering them unreachable for many (see Kangwana et al., 2009; Sudoi et al., 2012; Bagonza et al., 2015; Shacham et al., 2016)

${ }^{6}$ To cite just a few examples: in Zambia, more than 50 percent of rural women live at a distance of
} 
down the likelihood of a care-seeking visit.7 Indeed, a vast literature in epidemiology and public health has documented a strongly negative correlation between distance to the nearest health facility and utilization of health services, and a corresponding positive correlation between distance and mortality (World Development Report, 2004) Bumar et al. (2014) and Masters et al. (2013) document this correlation specifically for the case of institutional births (in India and Ghana respectively). While these cross-sectional correlations are informative, it has been hard to pin down causality as residential choices as well as clinic locations are usually endogenous, invalidating a causal comparison of outcomes for those located closer to health facilities and of those located far away from them.

In this paper, I provide the first causal evidence on the relationship between the distance to reproductive health-care facilities and service utilization by rural women in developing countries, and the subsequent impact of improved access on downstream outcomes. In order to do this, I utilize the phased roll-out of a large-scale, public road-construction program in rural India in a difference-in-differences framework. The program - the Prime Minister's Rural Road Program (henceforth, PMGSY, an abbreviation of the scheme's vernacular name), was launched at the end of the year 2000 and is still on-going. PMGSY created a federal mandate for all states to provide all-weather connectivity between all villages with a population of at least 500 and their nearest market center via paved roads 9 Since program eligibility was based on a population-based rule, it was less likely to suffer from the usual endogeneity concerns that plague the provision of public goods. Indeed, a number of recent papers have utilized the clean identification afforded by the PMGSY program to study causal impacts of road construction on a host of outcomes, including prices (Aggarwal, 2018), agricultural inputs and outcomes (Aggarwal, 2018; Shamdasani, 2017), labor markets (Aggarwal, 2018; Asher and Novosad, 2018), consumption (Aggarwal, 2018), and access to schools and human capital accumulation (Adukia et al., 2017).

10 kilometers or greater from a basic obstetric care facility (Gabrysch et al., 2011); in India, the average distance to the nearest primary health center was nearly 9 kilometers in 2008 (District Level Health Survey 3 ); in Pakistan, the average distance to a healthcare facility in rural areas in 2005 was 7 kilometers, going up to 10 kilometers for the poorest (Jain et al., 2015).

${ }^{7}$ It is plausible however that healthcare might be viewed as a necessity, due to which utilization may be fairly inelastic with respect to distance. That said, there is an additional mechanism through which distances will be important - the time to get care. In a recent paper, Gruber et al. (2018) show that reducing emergency department wait times by about $10 \%$ leads to a $14 \%$ reduction in mortality.

${ }^{8}$ Also, see Thaddeus and Maine (1994) and Gabrysch and Campbell (2009) for reviews. In the Economics literature, Friedman (2015) provides suggestive evidence of this relationship from Kenya, by showing that after the introduction of antiretroviral (ARV) drugs for HIV, risky health behaviors increased in villages with greater proximity to health care facilities, presumably due to easier access, and therefore, greater availability of ARVs. However, she is unable to empirically establish the first-stage effect due to data limitations.

${ }^{9}$ According to estimates provided by the Government of India, by the end of the 2013-14 fiscal year, approximately 400,000 kilometers of paved roads, connecting nearly 100,000 villages to their nearest market towns had been constructed (Ministry of Rural Development, 2015). 
The immediately intuitive identification strategy in this context would be to analyze healthcare utilization outcomes pre- and post-construction, for villages on either side of the eligibility cutoff. However, outcome data are from the District Level Health Survey (henceforth, DLHS), in which observations are identifiable only at the district-level, necessitating rolling-up program exposure to the district-level. I do so by relying on the fact that various districts in the country varied from each other in their baseline level of road provision as well as in the distribution of villages of different sizes, which generated exogenous variation in the percentage of population in each district that was exposed to the program every year 10 Identification is therefore underpinned by the assumption that pre- and post-natal care choices and outcomes of rural women are orthogonal to the size distribution of unconnected villages in their district of residence, allowing me to use differences in treatment intensity across districts and across time as my regressor of interest to study these outcomes.

I implement this diff-in-diff strategy in two closely related empirical specifications. In the first, I analyze outcomes for the full support of pregnant women observed in the data, as a function of the exposure to treatment for their district of residence in the year in which they delivered. In a second, more restrictive specification, I limit my sample to those households and/or women for whom I observe multiple childbirths during the sample period, and analyze outcomes for each of them as a function of the corresponding treatment exposure in the year of birth, while controlling for household- or mother-level fixed effects. By controlling for all household- and woman-level unobservables, this latter strategy allows me to recover a convincingly unconfounded treatment effect of roads. Moreover, for the full range of outcomes that I study, I find that the treatment effects across the two strategies are virtually identical, although at times underpowered in the specification with household/mother fixed effects.

In my main set of results, I show that road construction indeed lowered barriers to access, as evidenced by very large and significant increases in a pregnant woman's likelihood of visiting a formal health care facility for antenatal care (ANC) as well as for the delivery of her child $\boxplus$ Specifically, I find a 19 percentage point increase in the likelihood of an institutional delivery for the full support and 24 percentage point for households with multiple pregnancies (on a base of 32 percent and 40 percent respectively). I also find a 6 percentage point increase in the likelihood of seeking institutional ANC (IANC) at least once for the full sample and 7 percent for the restricted sample (on a base of 60 and 65 percent respectively). ${ }^{12}$ Tellingly,

\footnotetext{
${ }^{10}$ This identification strategy is identical to the one used in Aggarwal (2018), which studies the povertyalleviation impacts of the PMGSY program.

${ }^{11}$ It is worth mentioning here that while I focus largely on outcomes pertaining to maternal and child health services due to the nature of the data available, the gains from access on health outcomes will comprise a much bigger set.

${ }^{12}$ Unfortunately, the data are not structured to get at the number of institutional ANC visits, as each respondent is asked about the total number of care-seeking episodes over her pregnancy, and therefore, the
} 
the treatment effects on institutional delivery are stronger for children born during the rainy season as the benefit of having a paved road to travel to the hospital is likely greater during the rains (for instance, if unpaved roads could get washed away or flooded). Finally, although a rare event, I also find a significant reduction in the proportion of women reporting that they ended up delivering on the way to the hospital.

The second set of results shows that this better access to the formal health care sector translated into greater utilization of health care services and better outcomes for treatment seekers. This is an important contribution as the returns to inclusion in the formal healthcare sector are unclear in the setting being considered due to the poor quality of provision. Indeed, a large literature on service delivery in developing countries documents abysmal levels of provision, often times due to absenteeism, under-qualified providers, and perverse incentives (Banerjee et al., 2004; Chaudhury and Hammer, 2004; Chaudhury et al., 2006; Das et al. 2008; Das et al., 2012; Das and Hammer, 2013; Jayachandran, 2013; Muralidharan et al., 2011). 13 These grave inadequacies in the formal health sector beget a natural question without first fixing the quality of care issues, is better access to services in this sector even a policy goal worth pursuing? Indeed, Godlonton and Okeke (2016) show that while a ban on informal healthcare providers in Malawi led to a shift towards formal healthcare providers, it did not translate into any attendant benefits in terms of reduced child mortality. At the same time, there is competing evidence to suggest that the formal healthcare sector does lead to better outcomes, even in developing countries.14 The second part of my analysis therefore, lays some of these concerns about poor quality to rest by showing that following the road construction program, women were more likely to receive the recommended supplements and vaccinations during pregnancy, less likely to report having complications during child birth, and more likely to receive timely care during the post-natal period. Children are more likely to have received the recommended vaccinations.

Strikingly, I find that gains in the rates of institutional ANC and medically-supervised deliveries were concentrated only at public facilities, and were driven not just by the inclusion of those who had been outside the reach of the formal healthcare sector, but also by substitution towards public facilities by those using private providers. This stands to reason

answer combines both institutional and non-institutional episodes of antenatal care, including those provided by family and friends.

${ }^{13}$ In a recent audit study of a bednet distribution program in Ghana, Kenya, and Uganda, Dizon-Ross et al. (2018) do not find any evidence of corruption, suggesting that some of these problems might be less pervasive than what is conventionally believed.

${ }^{14}$ Specifically, Okeke and Chari (2017) show that Nigerian children who are born at home due to a nighttime delivery in areas which lack of 24-hour birthing facilities have a greater mortality rate; Friedman and Keats (2018) use data from 9 African countries to show that babies born during healthcare worker strikes are less likely to be born in-facility, and subsequently, have higher mortality rates. 
as rural India has a multi-step hierarchy of public health centers, serving successively larger areas and populations, and therefore, an average remote village (the kind that benefited from PMGSY), likely did not have any public health facility. According to the 2011 census, the average subcenter (the smallest level of public clinics in the country) serves nearly 5000 people, residing in 5 villages ${ }^{15}$ Aggarwal (2018) also documents that among villages that did not have roads at baseline, only 3 percent had a primary health center, and six percent had a maternal and child welfare center. The low density of public providers has implications for where households seek care: Gautham et al. (2011) and May et al. (2014) provide evidence from different parts of rural India showing that residents' first point of curative contact is with private individuals serving as unqualified practitioners of western-style medicine. ${ }^{16}$ Even in the specific case of pregnancy and child-birth, a number of studies document that women choose to go to traditional providers because formal providers are located far away ${ }^{17}$. Ray et al. (2011) document that households' "preference" for these providers is driven by cost and proximity factors, and that in an unconstrained environment, they would rather visit a public facility. Klemick et al. (2009) provide similar evidence from Tanzania showing that households often trade-off on quality and proximity while choosing doctors. Leonard (2007) shows that rural Tanzanians optimize on doctor quality by going to better doctors for more serious illnesses. Titaley et al. (2010) also document that Indonesian women reported that skilled birth-attendants and birthing facilities (which are located far away) are meant only for women with obstetric complications. In light of these, it makes sense that the road construction program caused households to switch to public providers, who were presumably farther, but of a higher quality.

These findings contribute to a large literature in health economics on the returns to health care spending in general, and hospital-based care in particular 18 as well as to a parallel, complementary literature on the impact of improved access to healthcare in developed countries (driven largely by changes in health insurance coverage). ${ }^{19}$ However, in their focus on mechanisms such as better hospital equipment or a longer stay in the hospital, these literatures have been concerned with the intensive-margin of treatment for those already within the reach of the formal health care sector. By turning my attention to marginal

\footnotetext{
${ }^{15}$ The corresponding numbers for Primary Health Centers (PHCs) and Community Health Centers (CHCs), the next category of facilities in the public health system is 31000 (31 villages) and 180000 (154 villages) respectively.

${ }^{16}$ As noted before, under-qualification of providers in the health sector is also documented in the service delivery literature by Das and Hammer (2014).

${ }^{17}$ See Titaley et al. (2010) for evidence from Indonesia, Anastasie et al. (2015) for evidence from Uganda, and Sialubanje et al. (2015) for evidence from Zambia.

${ }^{18}$ See Currie and Gruber (1996); Buchmueller et al. (2006); Almond et al. (2010); Almond and Doyle (2011); Doyle (2011).

${ }^{19}$ See Currie et al. (2008) and Card et al. (2009).
} 
patients instead, I provide estimates of the extensive-margin returns of having access to formal health care. In addition, I am able to extend the results of a predominantly developed country-focused literature to a developing country setting. In a recent paper, Adhvaryu and Nyshadham (2016) provide complementary evidence from Tanzania, where they exploit spatial and temporal variations in access to clinics, notably due to roads getting washed out during the rainy season, in order to show that children from families with better access to clinics are more likely to get timely treatment for malaria, and also more likely to stick with the treatment for longer. Moreover, most of this literature on access, including Adhvaryu and Nyshadham (2016), is focused on curative healthcare, and this paper is the first to extend these results to preventive healthcare.

Finally, this paper also contributes to an emerging literature on the impacts of rural roads in general, and of the PMGSY program in particular. Economic theory predicts that by reducing the pecuniary and opportunity costs of accessing goods and labor markets and government services, improvements in access will impact a whole host of choices made by rural households. Several empirical papers in the literature have tested and quantified these predictions in various settings ${ }^{20}$ but have focused largely on access to markets rather than public services. The existing literature on the PMGSY has also focused on market access as we expect that to be the primary mediator of economic outcomes. However, in rural areas of many developing countries, health and education are primarily the preserve of the public sector, and it is important to understand if road connectivity can improve the reach of nonmarket services. This paper extends the literature on rural roads by analyzing the impacts on access to and utilization of health care. In doing so, it also underscores the importance of roads as their impact on economic activity can be near-pervasive via improvements in access to a variety of markets and services.

The rest of this paper proceeds as follows. Section 2 provides institutional details about PMGSY. Section 3 discusses the data and identification strategy. In Section 4, I present falsification tests and main results, followed by a discussion of alternative hypotheses. Section 5 concludes.

\section{Institutional Details}

The PMGSY program was launched in December, 2000, with the aim to provide a paved all-weather road to all "habitations" 21 that had a population of at least 500 according to

\footnotetext{
${ }^{20}$ See Gibson and Rozelle, 2003; Dercon et al., 2009; Khandker et al., 2009; Gibson and Olivia, 2010; Ali, 2011; Khandker and Koolwal, 2011; Mu and van de Walle, 2011; Aggarwal et al., 2018.

${ }^{21}$ A "habitation" is defined as a cluster of population, whose location does not change over time. It is a sub-village level entity.
} 
the 2001 census 22 The program rules defined "all-weather connectivity" as having a paved road (with adequate drainage to withstand the Indian monsoon) within 500 meters of the habitation, and connecting it to either the nearest market center, or to another paved road leading to the market center. From hereon, for ease of exposition, I will use the words habitation and village interchangeably.

The funding for the scheme was provided by the federal government Even though this was a country-wide initiative led by the federal ministry of rural development, the actual construction was carried out by the states. In order to enable this, the federal government directed all states to identify a "core" network of roads, i.e., the minimal network required for all villages above the threshold for an area to have all-weather connectivity. The central government further required that within the core network, construction should be prioritized according to a population-based rule, wherein, villages with a population of 1000 or more were to be connected first, followed by those with a population of 500-1000, ultimately followed by those with a population of 250-500, and in descending order of population within each category. Villages from lower population categories could start getting connected only once all the villages in the immediately larger category in their state had already received roads. Exceptions were allowed if a smaller (by population category) village lay on the straight path of a road that was being built to a larger village. Upgrades of existing roads, though not central to the program, were allowed once all of the planned new construction was complete. ${ }^{24}$

This program is still on-going, but starting in the year 2011, the quasi-random portion of the intervention was somewhat diluted when the central government expanded the population eligibility criterion to include all villages with a population of 100 . In order to fund this large expansion in the scope of the project, the center required that the states co-fund the road construction activities, and the extent of this co-funding was largely determined by certain geographic and economic backwardness indicators of the state.25 As a result, starting in 2011, the road construction likelihood is no longer exogenously determined by village population alone, but also by the funds available with the respective states. The results of this paper are not impacted by this change however, as I only look at births up until the year 2009 .

Before we commence a serious causal investigation of the effects of the program, it must be

\footnotetext{
${ }^{22}$ This population threshold was lower (i.e., 250) in the case of areas pre-defined by the government of India as tribal, mountainous, or hilly.

${ }^{23}$ The funds were raised through a 1 Rupee per liter tax on high speed diesel. In addition, the central government has earmarked a fiscal outlay of $\$ 2.5$ Billion over and above the diesel tax. Finally, the World Bank and the Asian Development Bank have provided loans and financial assistance to the tune of a little over $\$ 2$ Billion.

${ }^{24}$ This paper does not include any upgrades, and is based solely on new road connectivity.

${ }^{25}$ Specifically, co-funding from the state was to the extent of $30 \%$ in the plains, $20 \%$ in hilly, desert, or tribal areas, as well as in economically backward districts in the plains, and 10\% in hilly areas located near the country's international borders.
} 
established that program rules were followed and there were no significant deviations. This is important to show because even though the empirical strategy is a diff-in-diff of treatment intensities across time and across districts (more on this in Section 3), the exogeneity in treatment intensities comes about because the treatment itself was based on a pre-specified rule. Causal inference would be invalid in this setting had the spatial and temporal allocation of roads been determined through endogenous economic, political, or social factors. While adherence to the PMGSY rules has now been shown by several authors of other studies on the impacts of the PMGSY program, including Adukia et al. (2017), Aggarwal (2018), Asher and Novosad (2018), and Shamdasani (2017), ${ }^{26}$ in the interest of completeness, however, I present here in Appendix Figure 1, a graph of the likelihood of having received a road under the PMGSY program by the year 2011 for villages in 100-wide population bins (please note that this figure is borrowed from Aggarwal (2018), where it is Figure 1). This figure confirms that the population-based rule was followed as the likelihood of road construction by 2011 is an increasing function of the village population, and exhibits discontinuous jumps at each of the population cutoffs.

I also reproduce from the same paper, Table A1 (Table A3 in Aggarwal, 2018), which combines PMGSY data with village-level information from the 2001 and 2011 censuses to document that villages that received a PMGSY road over the period 2001-2011 were no more likely to have received any other public goods during this period, other than a bus station, which was likely a direct consequence of having received a road. This table suggests that road construction was not driven by political influence as that should lead to differential receipt of other public goods also.

\section{Data \& Identification Strategy}

\subsection{Data}

\subsubsection{District Level Household Survey}

I use data from the rural module of 2 rounds of the District Level Household Survey (DLHS-2 and 3) in this paper, conducted in the years 2004 and 2009 respectively. The DLHS is the Indian version of the standard DHS survey.27 However, unlike DHS surveys in many other countries which track the same women over time, the DLHS is a repeated cross-section of

\footnotetext{
${ }^{26}$ While Lehne et al. (2018) document some corruption in the way the program was implemented, it was along the margin of who gets awarded the contract for building a road, and not along that of whether roads were built. On the latter, they show that more than 97 percent of the villages that should have received a paved road under the program, were found to have one during the 2011 Census of India.

${ }^{27}$ See https://dhsprogram.com/
} 
women (the panel nature is at the district-level). It is identical to the standard DHS in all other respects however, and contains retrospective birth histories of a representative sample of ever-married women in the age group 15-49. It is representative at the district-level, and the district is also the smallest identifiable geographical unit. The DLHS surveys are designed such that representative fertility histories are collected since the time of the last survey round, although the same women are not interviewed in successive survey rounds. Therefore, for women surveyed during DLHS-2, detailed birth histories over the period 1999-2003 were collected, and for those surveyed during DLHS-3, birth histories for the period 2004-2008 were collected. Since the pre-natal period for most of the births recorded in DLHS-2 falls in the pre-treatment period, I use this round of the survey for robustness and placebo checks only.

For all the women in DLHS-3 who report ever being pregnant during the period 2003 to 2008, there is basic data on each of these pregnancies, comprising of the outcome of the pregnancy, the date of birth/abortion, and the gender of the child. In addition, for the last child born to each woman, the survey has detailed data on the pre- and post-natal care, as well as the details of the delivery. For the last 2 children born, there is rich data on vaccinations. Finally, the survey also collects information on a host of covariates about the woman herself, her husband, and their household.

I use this data to create a district-level panel of births between the years 2004 and 2008. Specifically, even though the survey is conducted only at a point in time, since it asks women to provide details of all their pregnancies and deliveries over the past 5 years, the data can be turned into an annual panel of births over this period for all surveyed women. Please note that while this panel can be created for all the births that a surveyed woman had during the 2004-2008 period, detailed information on pre- and post-natal care, as well as delivery location and related details are collected only for the most recent birth, and therefore, the bulk of the analysis is on each woman's last birth. The empirical strategy therefore rests on the fact that each surveyed woman's last birth happened at different points in time during the survey period, and I attempt to uncover causality between road connectivity at the time of birth and the care-seeking decisions corresponding to that birth. The vaccination panel works similarly, except that vaccination information is collected for each woman's last two live births.

Since the DLHS survey is a retrospective panel of each surveyed woman's reproductive history, measurement error caused by recall bias is a concern, and this error will be greater the further back in time the event in question occurred. However, to the extent this recall bias is not systematically different across women residing in districts with different treatment intensities, the treatment effects will not be biased. Moreover, please note that Beckett et al. 
(2001) show that fertility histories tend not to suffer from recall bias, other than some amount of heaping, i.e., rounding off to the nearest "prototypical" value. Most of the outcomes that I consider in this paper are likelihoods, constructed based on answers to yes/no questions, and therefore, not likely to suffer from this bias. However, it is likely that the recall of self-reported transport costs is imperfect, and therefore, "heaped" to round numbers, but the likelihood and magnitude of heaping should not differ by treatment intensity.

\subsubsection{Online Management and Monitoring System}

In order to encourage scrutiny and accountability, all ministries of the government of India are increasingly being required to make data on the operations and performance of all large public programs publicly available. Under this initiative, the PMGSY was one of the first large programs for which detailed village-level data on road construction was made available by the Ministry of Rural Development on its website through a database called the Online Management and Monitoring System (OMMS). Therefore, for the universe of villages in India (irrespective of their baseline road status), I was able to download data on their baseline level of road-connectivity, population (in order to determine eligibility), whether they got a road under the program, and if so, the year in which the road was approved and built.

Since implementation quality was very likely endogenously determined by state capacity, and is therefore likely positively correlated with public health infrastructure and services in each state, I use the approval date as the date on which the road was built.

\subsection{Identification Strategy}

The DLHS is a district-level survey, wherein even though the unit of observation is the individual woman (or child, in case of vaccination outcomes), all identities are masked and aggregated up to the district. In other words, the smallest identifiable unit is each woman's district of residence. This implies that my empirical analysis can only be carried out at the district level. In order to do this, I aggregate the village-level connectivity variables up to the district-level, and employ a difference-in-differences strategy. Since we have already established that population rules were largely followed at the village level, such that whether or not a village benefited from the program is quasi-random, aggregating village connectivity up to the district and using it for causal analysis has inherent the assumption that the outcomes of interest are orthogonal to the size-distribution of unconnected villages in that district during the 2001 census. Specifically, this assumes that holding baseline connectivity fixed, health-seeking and utilization outcomes should not be different depending on whether the district's unconnected population lives in a few large villages or in many small ones. 
The analysis therefore, boils down to looking at the evolution of various outcomes, i.e., pre- and post-natal care as well as children's vaccination, as road connectivity improves over the 5-year period between 2004 and 2008. The independent variable of interest is the intensity of treatment in each district, which is defined as the percentage of each district's baseline rural population (i.e., as per the 2001 census) that had been approved to get a road under the program by that year. I create this variable by using the program data to get the total population of all villages in a district which were approved to get PMGSY roads up until that year and dividing that by the total population of all villages in that district.28

Therefore, my estimating equation is given by:

$$
y_{i d t}=\alpha+\mu_{m}+\gamma_{t}+\delta_{d}+\beta_{1} * P_{d t}+\eta_{1} Z_{i d t}+\varepsilon_{i d t}
$$

where subscript i denotes an individual (woman or child, depending on the outcome of interest), $d$ denotes district, $m$ denotes month of birth, and $t$ denotes year of birth. $\delta$ is a set of district fixed effects, $\gamma$ is a set of year fixed effects and $\mathrm{Z}$ is a vector of individual-level control variables. $P_{d t}$ is the variable of interest and captures the cumulative percentage of population in each district that had benefited from the road construction program by the year of birth in question. Since I observe outcomes for each successive year, $\beta_{1}$ ends up capturing the marginal effect of roads built in that year. All standard errors are clustered at the district level 29

While the smallest identifiable location unit for each woman is the district, the data do allow the mapping of all co-resident women to a single household. This is a particularly useful feature of the data for this study, as it allows me to obtain a household-level panel for those households where more than one woman reported being pregnant during the survey period. As a result, I can observe the choices made by a single household at different points in time, which allows me to abstract away from all household-specific factors that may affect utilization. For this set of households, the estimating equation is given by:

$$
y_{i h d t}=\alpha+\mu_{m}+\gamma_{t}+\kappa_{h d}+\beta_{2} * P_{d t}+\eta_{2} W_{i h d t}+\varepsilon_{i h d t}
$$

where all variables and subscripts are the same as in equation (1), and the additional

\footnotetext{
${ }^{28}$ Results stay qualitatively unchanged if I instead use the baseline unconnected population as the denominator. They also stay unchanged if I standardize the road connectivity variable to a z-score. Both of these are available upon request.

29 This empirical strategy is in fact identical to Aggarwal (2018), which also has outcomes aggregated up to the district.
} 
subscript $h$ denotes household. $\kappa$ is a set of household fixed effects and $\mathrm{W}$ is a vector of controls for each individual $i$ in household $h$.

Similar to the household-level identification described above for pre- and post-natal outcomes, I utilize the fact that vaccination information is sought for a woman's last 2 children born during the survey period, to create a mother-level panel. By doing so, I can use changes in PMGSY connectivity over each mother's inter-pregnancy interval to analyze her vaccination choices as a function of road connectivity. This is implemented empirically as described in equation (3) below:

$$
y_{i j d t}=\alpha+\mu_{m}+\gamma_{t}+\rho_{j d}+\beta_{3} * P_{d t}+\eta_{3} M_{i j d t}+\varepsilon_{i j d t}
$$

where all variables and subscripts are the same as in equation (1), and the additional subscript $j$ denotes mother. Individuals $i$ are children born during the year $t$ of the study period. $\mathrm{M}$ is a vector of controls and $\rho$ is a set of mother fixed effects. Please note, however, that this specification forces me to exclude all twin births since there is no variation in at-birth road connectivity between them.

In order to be conservative, standard errors continue to be clustered at the district level in specifications (2) and (3) also.

\section{Estimation Results}

\subsection{Baseline Characteristics and Covariates of Utilization}

Before we analyze the impact of roads on maternal and child care outcomes, it might be instructive to see how various covariates are related to these health outcomes. These results are presented in Table 1. In the first 2 columns of this table, I present the mean and standard deviations of the covariates themselves. We can see that the average woman ${ }^{30}$ who gave birth over the survey period was almost 20 years old at the birth of her first child. One half of the women had any schooling, and the average woman had had just below 3 pregnancies, and nearly as many live births till the date of the survey ${ }^{31}$ The households are predominantly agricultural, with $60 \%$ of the sample owning cattle, and nearly three-quarters owning agricultural land; the average holding size is just below 2 acres. They are also quite poor, as evidenced by asset and durable good ownership and the fact that more than a third of the households have a BPL card (i.e., they are officially recognized by the government as

\footnotetext{
${ }^{30}$ Please bear in mind that the sample is made up of rural women only.

${ }^{31}$ Please note however that child-bearing may not yet be over for many of these women as the survey coverage is for ever married women in the age group of 15 to 49 .
} 
being below the poverty line), although almost all the households report having their own house. The average household has about 7 members.

I next turn to analyzing the relationship between each of these covariates and health care. In columns 3 and 4, I report coefficients and standard errors from bivariate regressions of each of these variables on the likelihood of a woman delivering in an institutional health facility, and in columns 5 and 6 , I present the same estimates for the likelihood of a woman seeking IANC at least once during her last pregnancy. In looking at this table, we find that most estimates have the expected sign: richer, younger, and more educated women are more likely to seek IANC as well as to deliver in a hospital. Importantly, this table underscores that there are many significant predictors of take-up of institutional healthcare on the demandside. All of the analysis to follow will either control for these predictors directly or indirectly (through a household or woman fixed effect).

\subsection{Background and Falsification}

Before I analyze the impact of roads in a difference-in-differences framework, I must ensure that the parallel trends assumption is not violated. In order to do this, I follow the standard practice from the literature of running a falsification test by moving the treatment intensity variables to an earlier time period. Specifically, for each district, I assign their treatment intensity over the period 2004 to 2006 to corresponding years over the period 2001 to $20034^{32}$ I present these results in Tables 2 and 3, where Table 2 reports results from the falsification tests of pre- and postnatal care variables, and Table 3 reports the same for vaccination. All other controls and fixed effects are the same as in the main regressions to the extent that they are available in the DLHS-2. Fortunately, I do not find evidence of violations of the parallel trends assumption, which bolsters our confidence in the main results ${ }^{33}$ Also, as we will see below, in many cases, the coefficient for the falsification test is of the opposite sign relative to the main treatment effect. While this could raise concerns about mean reversion, please also note that the coefficients are small in absolute value relative to the main treatment effects of the program.

The impact of road construction on utilization of reproductive healthcare could potentially be confounded if fertility behavior changed as a result of the program. Changes in fertility are especially likely in this context as other work on the PMGSY program shows

\footnotetext{
${ }^{32}$ Even though the coverage for the DLHS-2 is 1999-2003, different versions of the survey instrument have conflicting instructions about the period prior to 2001, and therefore, data quality is reliable only for the 2001-2003 period.

${ }^{33}$ Aggarwal (2018) presents similar falsification tests for other non-health variables such as labor market participation which may also be potential confounders, further suggesting that these findings are not driven by pre-trends.
} 
that road construction expanded the availability of contraceptives in rural areas as well as increased women's labor force participation (Aggarwal, 2018). Therefore, before I start, I show that there was no causal impact of the roads program on women's fertility decisions. These results are presented in Table 4. Since I have the retrospective fertility history of each woman in the survey, I analyze the impact of road construction in each year on the likelihood that a woman was pregnant or gave birth to a child in the next year in Columns 1 and 2 respectively and do not find any significant effects. I also look at the impact on spacing between two successive births for those women who had two or more births during the sample period and find an increase in spacing of 0.2 years (or 2.5 months), corresponding to a 100 percent increase in road connectivity. Therefore, it seems that road connectivity does not cause women to alter the number of children they bear, but only increase the spacing between children, and therefore, outcomes on utilization of healthcare services should not be confounded by selection into fertility.

However, to the extent that the negative effect of roads on fertility is cause for concern (despite its insignificance), please note that for it to be able to explain the treatment effects on utilization outcomes like institutional deliveries (19 pp on a base of 32 percent), the effect on fertility would have to be at least an order of magnitude larger than what is presented in Table 4. Moreover, please note that if the results were being driven by sample composition changes due to selection into fertility, then I should not find within-household and withinmother effects, or differentially larger gains during the rainy season.

\subsection{Access}

An analysis of the impact of roads on health outcomes is predicated on the prior that the construction of roads would lead to increased accessibility to health care facilities. Therefore, a good place to start this analysis would be to establish that the construction of roads indeed led to such an improvement in access. While there are no questions in the survey that can help me directly establish that households had greater access to health facilities in the wake of the program ${ }^{34}$ am still able to look at whether households are more likely to utilize these facilities after road construction.Results are presented in Table 5. In Panel A, I report results from the regression specification given by Equation (1), and find that in going from not having a paved road to having one, there is an 19 percentage points increase in the likelihood of women delivering in a hospital, and a 6 percentage point increase in

\footnotetext{
${ }^{34} \mathrm{As}$ a matter of fact, the survey does ask questions about distance to the nearest health facility and whether it is accessible by road, however these are asked at the time of the survey and for that point in time only, and as a result available only for the cross-section. Expectedly, in the cross-section, districts with higher program intensity are those with lower density of public goods in general, including hospitals and clinics.
} 
the probability that she will seek institutional ante-natal care. Both of these gains are very large, and statistically different from zero. These numbers represent a 60 percent and 10 percent increase respectively, over baseline utilization rates ${ }^{35}$ At this point, it is also worth noting that roads brought about far larger gains in in-facility births relative to IANC - at baseline, about half as many women seeking IANC sought an in-facility delivery, but going from having no road to having one, takes this proportion to about 70 percent. Appendix Table A2 presents a cross-tabulation of the likelihoods of IANC and in-facility birth, and we observe that the subset of women who seek an in-facility birth, but not IANC is very small, suggesting that if someone is delivering in-facility, she must be a returning patient. Taken in conjunction with Columns 1 and 2 of Table 5, this suggests that while roads had an impact in terms of including women in the formal health sector (increase in IANC), their bigger impact was in bringing about persistent utilization (bridging the gap between IANC and in-facility delivery). This finding is in line with Adhvaryu and Nyshadham (2015), who show that a large part of the gains from better access for malaria treatment accrue via greater treatment adherence.

In addition, I am able to use a further proxy for measuring improvements in access: for women that do deliver in a hospital, the survey asks them how much they spent on transportation in order to get to the hospital. I summarize these in column 3 of Table 5 , Panel A. There is a large and statistically significant decrease of 224 Rupees in the amount spent by women in getting to the hospital. This represents an 71 percent decrease over baseline, a substantial reduction 36 While part of this reduction is due to better roads, there is also a part that would come about due to availability of public transportation, and unfortunately, it is not possible to disentangle the two. Specifically, Aggarwal (2018) uses the census of villages in India to show that villages that benefited from the PMGSY program were also much more likely to have received a bus station, a natural consequence of there being a road. For the women interviewed as part of this survey, having access to such means of transport may make the difference between having to hire a private vehicle to get to the birthing facility at considerable cost versus taking the bus. Moreover, please also note that the marginal user of the health facility is very likely poorer than average, and therefore, likelier to use cheaper means of transportation, due to which this coefficient may be larger than the actual reduction in transport costs. However, this does not jeopardize the primary

\footnotetext{
${ }^{35}$ This can alternatively be thought of in terms of network effects as some of the benefits of the program could also arise outside of the beneficiary villages, and because this paper uses district-level outcomes. For such an interpretation, the treatment effects would need to be scaled by the district-level treatment intensity, which was 0.7 at the mean. Therefore, in the average district, the in-facility delivery rate improved by 1.3 percentage points because of roads built under the PMGSY program.

${ }^{36}$ At the mean program connectivity of $7 \%$, this translates to a $5 \%$ reduction in transport costs to the hospital.
} 
finding - which is that access improved for the marginal patient. Having said all this, please also note that there is selection in the way this variable is recorded, so perhaps, not much should be made of this result 37

Since the mandate of the PMGSY program was to provide paved, all-weather roads, the resultant access improvements were likely larger during the monsoon season relative to the dry season when an unpaved road would be passable. Therefore, if we observe differential gains during the monsoon, that would be a strong test of the results being driven by access improvement due to roads. In order to do so, I create two dummy variables: the first for the monsoon season, which takes the value 1 if the woman delivered during the period between the standard onset and withdrawal dates of the southwest monsoon for her state of residence, as defined by the Indian Meteorological Department ${ }^{38}$ and a second "post monsoon" dummy for all deliveries during a month-long period after the official end of the monsoon for the state. This latter dummy allows for the fact that it takes some time for standing water to recede and for dirt roads to dry up and become serviceable again after the end of the monsoon. I run a fully interacted specification of these two dummies and the treatment intensity variable on the likelihood of an in-facility delivery ${ }^{39}$ Coefficients are reported in Column 4 of Table 5: I find that the treatment effect of roads on in-facility delivery is almost thrice as large in the monsoon and post-monsoon season as it is in the dry season.

In Panel B, I report coefficients from the same regressions as in Panel A, but with a restricted sample. Specifically, since the survey collects reproductive histories of all the women in the 15-49 age group for every household that is surveyed, we are able to observe the same household at multiple points in time if more than one women member of the household was pregnant during the survey period. This is particularly useful as it enables me to study household-level responses to better connectivity, after controlling for householdspecific unobservables ${ }^{40}$ After I restrict my dataset in this manner, I am left with just over 9000 households, with slightly over 19,000 pregnancies 41 This is a relatively under-powered estimation, with only 19,000 observations and household-level fixed effects, yet the treatment

\footnotetext{
${ }^{37}$ Please also note that transport cost to the birthing facility is recorded only for those that gave birth at the birth center. Therefore, if the program causes women who were earlier deterred from having an in-facility birth due to the high transport cost to now do so, their post-program transport costs would still be likely higher than the pre-program average transport cost. Similarly, if better roads induce women to travel farther to a better facility, their transport cost may not go down, and may in fact go up. In both cases, we are biased against finding a decrease in transport cost.

${ }^{38}$ Available at http://www.imd.gov.in/.

${ }^{39}$ This analysis cannot be done for IANC as at least some part of the pregnancy will always lie outside the monsoon season, which is at most 5 months long.

${ }^{40}$ In Appendix Table A3, I report the means of various covariates for the full sample as well as for the restricted sample described above.

${ }^{41}$ The number of pregnancies would not be exactly double the number of households as there may be a few cases where more than 2 women were pregnant in a household.
} 
effects persist and are stable in all 4 specifications, although they are no longer significant for likelihood of seeking IANC and for transport cost.

As the final piece of evidence in support of improved access, I show that the likelihood of a women delivering her child on the way to the health facility goes down. These results are presented in Table 6. Expectedly, this is a relatively rare phenomenon, and at baseline, less than half a percent of all pregnant women delivered on the way to the hospital. Road construction led to a large and statistically significant drop in this likelihood, potentially through reducing unexpected delays on the way to the hospital or by reducing the effective distance to the hospital, thereby allowing some of those women who either did not leave for the hospital well in advance or for whom labor progressed faster than expected to arrive at the hospital in time for the birth, rather than after.

\subsection{Health Outcomes}

Having established that roads led to improved access, I now turn to the second part of my analysis which pertains to health outcomes for those who got included in the formal health care sector due to roads. As summarized above, the public health care system in India is fraught with corruption, and patients often do not receive the care and services they seek. In such a scenario, improved access might not be sufficient to lead to improvements in health outcomes.

\subsubsection{Pre- and post-natal care}

In Table 7, Panel A, I start by looking at various aspects of services received as a function of roads built. Columns 1-5 pertain to various aspects ofantenatal services which are understood to improve maternal and child outcomes. In column 1, I report the likelihood that a woman was provided at least 1 of 8 services during her pre-natal period, while column 2 reports the count of the number of ANC services provided (out of a maximum possible of 8) 42 and column 3 reports the likelihood that the woman received advice on any of the suite of good pre-, peri-, or post-natal good practices during her pregnancy ${ }_{43}^{4}$ Columns 4 and 5 report the binary likelihood of having received tetanus shots and supplements for iron, folate, and

\footnotetext{
${ }^{42}$ This includes basic services like measurement of height, weight, and blood pressure, to slightly more advanced services like blood and urine tests and breast examination, to very advanced services like an ultrasound and sonogram.

${ }^{43}$ These include information around (a) vaginal bleeding, (b) convulsions, (c) prolonged labor, (d) where (health facility) to go if faced with any pregnancy complications, (e) delivery date (f) delivery advice (g) nutrition advice, (h) breastfeeding, (i) keeping the baby warm, (j) the need for cleanliness at the time of delivery, (k) Family planning for spacing, (l) family planning for limiting, (m) better nutrition for mother and child, and (n) need for institutional delivery.
} 
calcium. I find that once roads are constructed women are indeed more likely to receive better quality prenatal care: they are more likely to receive micronutrient supplements, more likely to receive tetanus shots, and also more likely to receive advice on good practices on self-care and family planning. I do not find any evidence that there was an increase in the likelihood of having received some form of ANC check-up, but I find a negative and statistically insignificant effect on the number of prenatal services received (Column 2). This makes sense as the inclusion of women from remote areas in the formal health system will likely bring down the average utilization of high end services like say, ultrasounds, as clinics in remote areas are unlikely to have such facilities.

Access improvements also resulted in measurable gains during child-birth. This can be seen in Column 6 of Table 7 - I find that when a district moves to full connectivity, its women report a 4 percentage point reduction in the likelihood that they had complications during delivery, where a complication is defined as the likelihood that the woman reported having excessive bleeding or convulsions/high blood pressure. Given the high probability that a woman is more likely to be aware of the fact that there were complications in her delivery when she delivers under medical supervision, this number actually represents a lower bound on the reduction in delivery complications brought about by the building of roads. Finally, I also show in columns 7 and 8 of the same table that there was a 14 percentage point increase in the likelihood of either the mother or the child receiving timely checkup in the postnatal period, and an 11 percentage point increase in the likelihood of both receiving a timely checkup. Here, timely checkup refers to whether there was a check-up by a doctor within 48 hours of delivery.

In Panel B, I examine all of the same variables as in Panel A, but similar to this panel in Table 2, I restrict my sample to only those households where multiple women were pregnant during the survey period, and were therefore subject to varying levels of road connectivity while making their decisions. Even though the treatment effects lose their significance because of the restrictive nature of this specification, not only is the direction of the coefficients is preserved, the point estimates between Panels A and B are very stable across the full range of outcomes.

A major concern with interpreting these results is that it may be hard to disentangle the mechanisms at work. I hypothesize that medical care utilization improved as a result of better access to the clinics - a demand side improvement. However, it is also likely that some of the improvements came about due to potential decreases in absenteeism - if the nurse is present on a greater number of days, she is likely to assist more patients. While absence rate decreases also likely came about due to better access, this channel is a supply side one with very different policy implications. 


\subsubsection{Vaccination}

An important aspect of public health delivery in developing countries is providing adequate vaccination coverage. This is for good reason - according to public health experts, vaccinations rank second after clean water in their ability to reduce the global burden of infectious diseases. However, despite concerted national and international efforts, population coverage rates remain significantly lower than the 95 percent required to eliminate infectious diseases. In rural India, the context under study, coverage rates varied from 24 percent for the hepatitis vaccine, and over 90 percent for polio in 2004 (Table 8). Therefore, it would be interesting to see if improvements in access that led to greater utilization of medical services by women, also led to a similar expansion in vaccination rates for kids. I present such an analysis in Panel A of Table 8, where I analyze administration rates for a range of different vaccines that are given to children during their first year. I find strong, positive effects across the entire gamut of vaccines: children are more likely to have a vaccination card issued by a health care facility, and also more likely to have received vaccines for BCG, DPT, measles, vitamin A, hepatitis, and polio. The effect sizes are large, and range from a 13 percentage point increase in the DPT vaccination rate, to a 34 percentage point increase in the rate for measles. I do not find any gains in the case of the polio vaccination rate, but the baseline coverage rates for polio were already quite high. This is likely because the government of India has been running a massive initiative to attain universal polio vaccination rates since $19954_{4}^{44}$ Therefore, roads are unlikely to have improved access to polio vaccination. Finally, in Panel B, I report these results for the restricted sample of women, who had at least 2 kids in the sample period. While the survey collects detailed pre- and post-natal care information only for a woman's last pregnancy, information on vaccination is collected for each woman's last 2 children, born during the sample period. I utilize this information to create a motherlevel panel and implement a difference-in-differences strategy with mother fixed effects. The treatment effects on vaccination rates continue to be large and statistically significant even for this sample 45

\subsection{Substitution Behavior}

Another implication of better access to nearby markets is that the number of treatment facility options should weakly increase. Therefore, we can gain insights into household preferences

\footnotetext{
${ }^{44}$ The last known case of polio in India was in 2011, and the country was officially declared as having eradicated polio in the year 2014 .

${ }^{45}$ There may be concerns that the effect is confounded by mothers learning about vaccination from their experience with their older child(ren). However, the learning effect should not be differential across districts with varying treatment intensities.
} 
by looking at switching between providers. Specifically, if households switch from provider A to provider B, then B is revealed preferred to A. So, for instance, if we find that when access improves, households like to visit private providers instead of public providers, then a public policy implication might be to spend resources on providing vouchers for private clinics, instead of expanding subsidized medical care. With that in mind, I turn the readers' attention to Table 9 which analyzes precisely this kind of switching behavior. I find that the program induces households to switch away from private, and towards public hospitals for both deliveries as well as for prenatal care. These effects are even bigger when conditioning on prior use of institutional care, and are shown in in Columns 3 and 4 . The structure of the data also allows me to explore this switching behavior in greater detail, as the survey seeks information on the kind of public facility at which care was sought. I present these results in Table 10 for in-facility deliveries and in Table 11 for IANC. I want to start by discussing Panel A of both of these tables, which considers the full sample of pregnant women.I find that in the case of ante-natal care, the entirety of the switch is from private facilities to subcenters (SCs), the smallest and most local level of public health facility. In the case of deliveries, on the other hand, women also switch to Primary Health Centers (PHCs) and to district hospitals, providers that are located much farther away (SCs serve 5 villages on average, PHCs serve 31, and the lowest level of public hospital serves a 1000 villages).

These results sit well with the way health care facilities are currently organized in rural India. As explained in the introduction, there is a large dearth of public clinics, which has led to a mushrooming of low-quality private providers. It has been documented that despite being aware of their poor quality, care-seekers often visit these providers due to convenience and proximity reasons. This phenomenon is very similar to the ones documented by Leonard (2007) and Klemick et al. (2009).

However, once access improves, households choices are less constrained, taking them closer to the optimum.

One could be concerned that these results are driven, not by actual substitution, but by changing sample composition, such that the newly included mothers can only afford public facilities. In order to examine this, I now turn to Panel B of Tables 10 and 11, which replicate the analysis in Panel A, but with the restricted sample of households with multiple pregnant women. We find that even at the household-level, with the geographic location of the households and the distance to the clinics unchanged, the substitution patterns still hold up. 


\subsection{Alternative Hypotheses}

There could be concerns that the mechanism behind the results presented above is something other than access. Notably, the PMGSY program had far-reaching consequences in the village economy, for instance, on income. Therefore, it is possible that behavior changes are being driven by income. However, the private-public substitution lays some of these concerns to rest. Given the poor state of affairs in public facilities, a greater income is usually correlated with higher use of the private sector. My results to the contrary suggest that income is not the driving factor.

Companion papers on the impacts of PMGSY show that the program brought about increases in women's labor market participation (Aggarwal, 2018). There is a large literature in development economics that shows that increased labor market opportunities for women translate into greater autonomy and bargaining power (for instance, Anderson and Eswaran, 2009; Jensen, 2012). There might therefore be concerns that these effects may be mediated through women's increased autonomy, and may not be a direct result of improved access. The differential gains for children born during the monsoon season are reassuring in that regard as those are unlikely to be driven by intra-household bargaining. Moreover, increased autonomy is more likely to lead to extensive margin effects, i.e., cause women to visit the formal healthcare sector for the first time, but much less likely to cause increases on the intensive margin of visits, unless the decision to visit the hospital is negotiated anew before each impending visit. Increased autonomy should also not bring about provider switching from private to public. Finally, the finding that transport costs reduced suggests that results are not being driven entirely by increased autonomy.

Another cause for concern is that the PMGSY program was largely contemporaneous with the Janani Suraksha Yojana (JSY), the government of India's flagship conditional cash transfer program to encourage institutional births. The JSY has been shown to have large positive effects on the rate of in-facility births in the country. While it is impossible to rule out that the effects shown in this paper do not owe part of their genesis to the JSY, the same reasons as above - greater institutional births during the monsoon and a reduction in transport costs again bolster our confidence that some of the gains are due to improved access.

As a further test I analyze the household's likelihood to seek medical treatment for other diseases (the DLHS survey includes questions on diarrhea and fever), which should not be impacted by JSY. These results are presented in Table 12. Please note that the research design that has been followed so far in this paper cannot be used to analyze these impacts as there is no time variation in this variable. Instead, each household, at the time of their interview, is asked whether a child has been sick with fever or diarrhea in the past 2 weeks, 
and if so, whether the household sought treatment for the disease. As a result, a multi-year panel cannot be constructed ${ }^{46}$ I circumvent this data limitation by utilizing variation in the exact timing of the interview - specifically, greater treatment intensity is likely to be more helpful during the monsoon season. During the dry season, even an unpaved road can easily be traversed. Therefore, similar to the strategy in Table 5, I create a monsoon dummy, which takes the value 1 if the household was interviewed during the monsoon, and 0 otherwise; and a post-monsoon dummy for the 1 month period after the monsoon. I interact this dummy with treatment intensity at the time of the interview, and this is my variable of interest. Results are reported in Table 12. The treatment effects are positive, but suffer from low statistical power on two accounts - the low incidence of these diseases in the first place and the low likelihood of there being an interview during the monsoon (less than $20 \%$ of the households were interviewed during the monsoon season). Therefore, once roads are built, beneficiaries are able to seek treatment for other diseases, an outcome that should be entirely orthogonal to the JSY program. All this being said, while the exact magnitudes of the PMGSY and the JSY programs cannot be teased apart, since receipt of JSY benefits was conditional on delivering in a health facility, by easing access to these facilities, the PMGSY program likely made it easier for women to benefit from JSY. Fortunately, the DLHS includes questions on whether the woman received JSY benefits. I use this as an outcome variable, and report the results in Table 13. Women who benefited from the PMGSY were 34 percentage points more likely to report that they received a JSY cash transfer, suggesting that improved access enabled women to take advantage of other government programs.

As a final test to establish that these findings are driven by improved access, I follow Asher and Novosad (2018) to divide the states of the country into good versus bad implementers of the PMGSY program, and show that treatment effects are obtained only by the good implementers. Specifically, Asher and Novosad (2018) show that 6 states - Chhattisgarh, Gujarat, Madhya Pradesh, Maharashtra, Odisha, and Rajasthan - adhered strictly to the village-level population thresholds defined by the federal government, while the other states deviated to varying degrees. Therefore, if we find any results for the states that implemented the program poorly, then the results are more likely to be driven by omitted variables. I show these results in Appendix Table A4, where I interact the treatment intensity variable with a dummy for "good implementer" states. It can be seen that the gains in institutional births as well as ANC are driven entirely by these states. Surprisingly, transport costs do not differentially decrease for the good implementers, suggesting that while the marginal woman in poor implementation states did not benefit from PMGSY, those who already had access

\footnotetext{
${ }^{46}$ Please note that I also cannot include a district fixed effect as it is now collinear with the treatment intensity at the time of the interview, and therefore, include a state fixed effect for this specification.
} 
did experience a reduction in transport costs even in these states.

\section{Conclusion}

In this paper, I use district-level variation in road pavement intensity in rural areas, induced by the rules of a large scale road construction program of the government of India, to show that roads improved access to healthcare facilities. Contrary to popular perceptions about the state of affairs at these healthcare facilities, improved access led to pregnant women receiving better care and subsequently, having better health outcomes, such as a lower rate of delivery complications. Children are also more likely to be vaccinated. I find that these results are robust to looking within household or within mother in cases where a household had multiple pregnant women or a woman had multiple births during the sample period.

These results have important implications for healthcare policy in developing countries. Improving maternal and child health has been an important and long-standing goal, and while significant strides were made in this direction in the run-up to 2015 (the target date for achieving the Millennium Development Goals), much remains to be accomplished at the country-level as well as for those who are socially and economically marginalized within developing countries. It has been proposed that easing supply-side bottlenecks would encourage the utilization of health services and improve outcomes, and that these policies are likely to benefit economically disadvantaged women the most as they tend to be severely access constrained (WHO, 2015). On-the-ground gains in this regard, however, have been hard to accomplish. This paper is the first to provide evidence that some of these constraints can be resolved by improving physical access to clinics and health facilities.

This paper also adds to an emerging literature on the social and economic impacts of rural roads in general, and the PMGSY program in particular. In previous papers on the impacts of the PMGSY program (Adukia et al., 2017; Aggarwal, 2018; Asher and Novosad, 2018; Shamdasani, 2017) it has been shown that this program led to increases in household consumption, educational attainment, technology adoption, labor force participation rates, and may even have hastened the process of structural transformation in the countryside. Taken in conjunction with the older results, the findings from this paper suggest that road construction unambiguously improves households' access to and utilization of markets (both goods and labor) and services, and is very likely welfare enhancing.

The focus of this paper as well as of the larger literature, however, has been on short-term effects (largely because PMGSY is a recent program). Given the large documented impacts on education, occupation choice, technology adoption, and healthcare utilization, PMGSY will likely lead to large long-term benefits, which must be the focus of future research in this 
area. Moreover, many of these outcomes have all been studied in isolated partial equilibrium settings, and the general equilibrium effects of roads are yet to be understood. 


\section{References}

[1] Adhvaryu, Achyuta (2014). Learning, Misallocation, and Technology Adoption: Evidence from New Malaria Therapy in Tanzania. The Review of Economic Studies 81(4), 1331-1365

[2] Adhvaryu, Achyuta and Anant Nyshadham (2015). Returns to Treatment in the Formal Health Care Sector: Evidence from Tanzania. American Economic Journal: Economic Policy 7(3), 29-57

[3] Adukia, Anjali, Samuel Asher, and Paul Novosad (2017). Educational Investment Responses to Economic Opportunity: Evidence from Indian Road Construction.Working Paper.

[4] Aggarwal, Shilpa (2018). Do Rural Roads Create Pathways out of Poverty? Evidence from India. Journal of Development Economics 133, 375-395.

[5] Aggarwal, Shilpa, Brian Giera, Dahyeon Jeong, Jonathan Robinson, and Alan Spearot (2018). Market Access, Trade Costs, and Technology Adoption: Evidence from Northern Tanzania. Working Paper.

[6] Al-Taiar, Abdullah, Allan Clark, Joseph C. Longenecker, and Christopher Whitty (2010). Physical Accessibility and Utilization of Health Services in Yemen. International Journal of Health Geographics 9 (38).

[7] Almond, Douglas and Joseph Doyle (2011). After Midnight: A Regression Discontinuity Design in Length of Postpartum Hospital Stays. American Economic Journal: Economic Policy 3 (3), 1-34.

[8] Almond, Douglas, Joseph Doyle, Amanda Kowalski, and Heidi Williams (2010). Estimating Marginal Returns to Medical Care: Evidence from At-risk Newborns. Quarterly Journal of Economics 125 (2), 591-634.

[9] Anastasi, Erin, Matthias Borchert, Oona Campbell, Egbert Sondorp, Felix Kaducu, Olivia Hill, Dennis Okeng, Vicki Odong, and Isabelle L. Lange (2015). Losing women along the path to safe motherhood: why is there such a gap between women's use of antenatal care and skilled birth attendance? A mixed methods study in northern Uganda. BMC Pregnancy Childbirth 15 (287).

[10] Anderson, Siwan and Mukesh Eswaran (2009). What Determines Female Autonomy? Evidence from Bangladesh. Journal of Development Economics 90 (2), 179-191.

[11] Asher, Samuel and Paul Novosad (2018). Rural Roads and Structural Transformation. Working Paper. 
[12] Banerjee, Abhijit, Angust Deaton, and Esther Duflo (2004). Health Care Delivery in Rural Rajasthan. Economic and Political Weekly, 944-949.

[13] Banerjee, Abhijit, Esther Duflo, Rachel Glennerster, and Dhruva Kothari (2010). Improving Immunization Coverage in Rural India: A Clustered Randomized Controlled Evaluation of Immunization Campaigns with and without Incentives. British Medical Journal 340:c2220.

[14] Barham, Tania and John A. Maluccio (2009). Eradicating Diseases: The Effect of Conditional Cash Transfers on Vaccination Coverage in Rural Nicaragua. Journal of Health Economics 28 (3), 611-621.

[15] Beckett, Megan, Julie DaVanzo, Narayan Sastry, Constantijn Panis, and Christine Peterson, 2001. The quality of retrospective data: an examination of long-term recall in a developing country. Journal of Human Resources 36 (3), 593-625

[16] Buchmueller, Thomas C., Mireille Jacobson, and Cheryl Wold (2006). How Far to the Hospital? The Effect of Hospital Closures on Access to Care. Journal of Health Economics 25 (4), 740-761.

[17] Card, David, Carlos Dobkin, and Nicole Maestas (2009). Does Medicare Save Lives? Quarterly Journal of Economics 124, 597-636.

[18] Chaudhury, Nazmul and Jeffey Hammer (2004). Ghost Doctors: Absenteeism in Rural Bangladeshi Health Facilities. World Bank Economic Review 18 (3), 423-441. 20

[19] Chaudhury, Nazmul, Jeffey Hammer, Michael Kremer, Karthik Muralidharan, and F.Halsey Rogers (2006). Missing in Action: Teacher and Health Worker Absence in Developing Countries. Journal of Economic Perspectives 20 (1), 91-116.

[20] Cohen, Jessica and Pascaline Dupas (2010). Free Distribution or Cost-Sharing? Evidence from a Randomized Malaria Experiment. Quarterly Journal of Economics 125 (1), $1-34$.

[21] Currie, Janet, Sandra Decker, and Wanchuan Lin (2008). Has Public Health Insurance for Older Children Reduced Disparities in Access to Care and Health Outcomes? Journal of Health Economics 27, 1567-1581.

[22] Currie, Janet and Jonathan Gruber (1996). Health Insurance Eligibility, Utilization of Medical Care, and Child Health. Quarterly Journal of Economics 111 (2), 431-466.

[23] Dammert, Ana, Jose Galdo, and Virgilio Galdo (2014). Preventing dengue through mobile phones: Evidence from a field experiment in Peru. Journal of Health Economics $35,147-161$ 
[24] Das, Jishnu, Alka Holla, Veena Das, Manoj Mohanan, Diana Tabak, and Brian Chan (2012). In urban and rural india, a standardized patient study showed low levels of provider training and huge quality gaps. Health Affairs 31 (12), 2774-2784

[25] Das, Jishnu and Jeffey Hammer (2005). Which Doctor? Combining Vignettes and Item Response to Measure Clinical Competence. Journal of Development Economics 78 (2), 348-383.

[26] Das, Jishnu and Jeffey Hammer (2007). Money for Nothing: The Dire Straits of Medical Practice in India. Journal of Development Economics 83 (1), 1-36.

[27] Das, Jishnu and Jeffey Hammer (2014). Quality of Primary Care in Low-Income Countries: Facts and Economics. Forthcoming, Annual Review of Economics.

[28] Das, Jishnu, Jeffey Hammer, and Kenneth Leonard (2008). The Quality of Medical Advice in Low-Income Countries. Journal of Economic Perspectives 22 (2), 93-114.

[29] Dhillon, R.S., M.H. Bonds, M. Fraden, D. Ndahiro, and J. Ruxin (2012). The Impact of Reducing Financial Barriers on Utilisation of a Primary Health Care Facility in Rwanda. Global Public Health 13 (1), 71-86.

[30] Dizon-Ross, Rebecca, Pascaline Dupas, and Jonathan Robinson (2014). Governance and Effectiveness of Public Health Subsidies. Working Paper.

[31] Dongre, Ambrish (2012). Can Conditional Cash Transfers Impact Institutional Deliveries? Evidence from Janani Suraksha Yojana in India. Working Paper.

[32] Doyle, Joseph (2011). Returns to Local-Area Emergency Health Care Spending: Using Health Shocks to Patients Far From Home. American Economic Journal: Applied Economics 3 (3), 221-243.

[33] Dupas, Pascaline (2011). Do Teenagers Respond to HIV Risk Information? Evidence from a Field Experiment in Kenya. American Economic Journal: Applied Economics 3 (1), 1-36. 21

[34] Dupas, Pascaline and Jonathan Robinson (2013). Why Don't the Poor Save More? Evidence from Health Savings Experiments. American Economic Review 103 (4), 1138-1171.

[35] Durairaj, Varatharajan, Sidhartha R. Sinha, David B. Evans, and Guy Carrin (2010). Shaping National Health Financing Systems: Can Micro-Banking Contribute? World Health Report 2010, Background Paper.

[36] Friedman, Willa (2014). Antiretroviral Drug Access and Behavior Change. Working Paper. 
[37] Friedman, Willa and Anthony Keats (2018). "What can we learn from babies born during healthworker strikes?" Working Paper.

[38] Gabrysch, Sabine and Oona Campbell (2009). Still too Far to Walk: Literature Review of the Determinants of Delivery Service Use. BMC Pregnancy and Childbirth 9 (34).

[39] Gabrysch, S., S. Cousens, Cox J., and Campbell O.M.R. (2011). The Inuence of Distance and Level of Care on Delivery Place in Rural Zambia: A Study of Linked National Data in a Geographic Information System. PLoS Medicine 8 (1): e1000394.

[40] Gautham, Meenakshi, Erika Binnendijk, Ruth Koren, and David. M. Dror (2011). 'First we go to the Small Doctor': First Contact for Curative Health Care sought by Rural Communities in Andhra Pradesh \& Orissa, India. Indian Journal of Medical Research $134,627-638$.

[41] Godlonton, Susan and Edward Okeke (2016) Does a Ban on Informal Health Providers Save Lives? Evidence from Malawi. Journal of Development Economics 118, 112132.

[42] Gruber, Jonathan, Thomas Hoe, and George Stoye (2018). "Saving Lives by Tying Hands: The Unexpected Effects of Constraining Health Care Providers." Working Paper.

[43] Jayachandran, Seema (2014). Incentives to Teach Badly? After-School Tutoring in Devel- oping Countries. Forthcoming, Journal of Development Economics.

[44] Jensen, Robert (2012) Do Labor Market Opportunities Affect Young Women's Work and Family Decisions? Experimental Evidence from India. Quarterly Journal of Economics 127(2), 753-792.

[45] Klemick, Heather, Kenneth L. Leonard, and Melkiory C. Masatu (2009). Defining Access to Health Care: Evidence on the Importance of Quality and Distance in Rural Tanzania. American Journal of Agricultural Economics 91 (2), 347-358.

[46] Lagarde, M., A. Haines, and N. Palmer (2007). Conditional Cash Transfers for Improving Uptake of Health Interventions in Low- and Middle-Income Countries: a Systematic Review. Journal of American Medical Association 298 (16), 1900-1910.

[47] Leonard, Kenneth (2007). Improving Health Outcomes By Choosing Better Doctors: Evi- dence of Social Learning about Doctor Quality from Rural Tanzania. Working Paper. 22

[48] Luo, Renfu, Yaojiang Shi, Linxiu Zhang, Huiping Zhang, Grant Miller, Alexis Medina, and Scott Rozelle (2012). The Limits of Health and Nutrition Education: Evidence 
from Three Randomized-Controlled Trials in Rural China. CESifo Economic Studies 58 (2), 385-404.

[49] May, C., K. Roth, and Panda P. (2014). Non-degree Allopathic Practitioners as First Contact Points for Acute Illness Episodes: Insights from a Qualitative Study in Rural Northern India. BMC Health Services Research 14: 182.

[50] Meredith, Jennifer, Jonathan Robinson, Sarah Walker, and Bruce Wydick (2013). Keeping the Doctor Away: Experimental Evidence on Investment in Preventative Health Products. Journal of Development Economics 105, 196-210.

[51] Ministry of Rural Development (2015). "PMGSY Budget Briefs, 2014." New Delhi, India.

[52] Morris, S.S., Flores F., Olinto P., and Medina J.M. (2004). Monetary Incentives in Primary Health Care and effects on Use and Coverage of Preventive Health Care Interventions in Rural Honduras: Cluster Randomized Trial. Lancet 364, 2030-2037.

[53] Muralidharan, Karthik, Nazmul Chaudhury, Jeffey Hammer, Michael Kremer, and F. Halsey Rogers (2011). Is there a Doctor in the House? Absent Medical Providers in India. Working Paper.

[54] New York Times (2012). India's Hidden Health Care Labor Force. http://india.blogs.nytimes.com/2012/11/29/indias-hidden-health-care-labor-force. Accessed on May 26, 2014.

[55] Okeke, Edward, A.V. Chari, Akinfolarin Adepiti (2016) Does Price Affect the Demand for Information about New Health Technologies? Evidence from a Field Experiment in Nigeria. Economic Development and Cultural Change, 64(3), 2016

[56] Okeke, Edward, Clement Adepiti, Kayode Ajenifuja (2013) "What is the Price of Prevention? New Evidence from a Field Experiment," Journal of Health Economics, 32, 2013

[57] Palmer, Natasha, Dirk H. Mueller, Lucy Gilson, Anne Mills, and Andy Haines (2004). Health Financing to Promote Access in Low Income Settings - How Much Do We Know? Lancet 364 (9442), 1365-1370.

[58] Patil, Ashok V., K. V. Somasundaram, and R. C. Goyal (2002). Current Health Scenario in Rural India. Australian Journal of Rural Health 10, 129-135.

[59] Paxson, Christina and Norbert Schady (2010). Does Money Matter? The effects of Cash Transfers on Child Development in Rural Ecuador. Economic Development and Cultural Change 13 (1), 187-229. 23 
[60] Ray, S.K., S.S. Basu, and A.K. Basu (2011). An Assessment of Rural Health Care Delivery System in some Areas of West Bengal - an Overview. Indian Journal of Public Health 55 (2), 70-80.

[61] Robertson, L., P. Mushati, J.W. Eaton, L. Dumba, G. Mavise, J. Makoni, C. Schumacher, T. Crea, R. Monasch, L. Sherr, G.P. Garnett, C. Nyamukapa, and S. Gregson (2013). Effects of Unconditional and Conditional Cash Transfers on Child Health and Development in Zimbabwe: a Cluster-Randomised Trial. Lancet 381, 1283-1292.

[62] Rocha, Romero and Rodrigo R. Soares (2010). Evaluating the Impact of CommunityBased Health Interventions: Evidence from Brazil's Family Health Program. Journal of Health Economics 19 (S1), 126-158.

[63] Sialubanje Cephas, Karlijn Massar, Davidson Hamer, and Robert Ruiter (2015). Reasons for home delivery and use of traditional birth attendants in rural Zambia: a qualitative study. BMC Pregnancy Childbirth 15 (216).

[64] Shamdasani, Yogita (2016). Rural Road Infrastructure and Agricultural Production: Evidence from India. Unpublished.

[65] Tarozzi, Alessandro, Aprajit Mahajan, Brian Blackburn, Dan Kopf, Lakshmi Krishnan, and Joanne Yoong (2013). Micro-Loans, Bed Nets and Malaria: Evidence from a Randomized Controlled Trial. Forthcoming, American Economic Review.

[66] Thaddeus, S. and D. Maine (1994). Too far to Walk: Maternal Mortality in Context. Social Science and Medicine 38 (8), 1091-1110.

[67] Thornton, Rebecca (2008). The Demand for, and Impact of, Learning HIV Status. American Economic Review 98 (5), 1829-1863.

[68] Titaley, C., C. Hunter, M. Dibley, P. Heywood (2010). Why do some women still prefer traditional birth attendants and home delivery? A qualitative study on delivery care services in West Java Province, Indonesia. BMC Pregnancy Childbirth 10 (43), 1-14.

[69] Travis, Phyllida, Sara Bennett, Andy Haines, Tikki Pang, Zul_qar Bhutta, Adnan A Hyder, Nancy R. Pielemeier, Anne Mills, and Timothy Evans (2004). Overcoming Health-Systems Constraints to Achieve the Millennium Development Goals. Lancet 364, 900-906.

[70] Wagstaff, Adam and Mariam Claeson (2004). The Millennium Development Goals for Health: Rising to the Challenges. The World Bank, Washinton, DC.

[71] WHO (2012). Building a Future for Women and Children: The 2012 Report. World Health Organization and UNICEF, Geneva, Switzerland. 
[72] WHO (2015). State of Inequality: Reproductive, Maternal, Newborn, and Child Health. World Health Organization, Geneva, Switzerland.

[73] World Bank (2004). World Development Report 2004: Making Services Work for Poor People. The World Bank and Oxford University Press.

[74] UNICEF (2018). Every Child Alive: The Urgent Need to End newborn Deaths. UNICEF, Geneva, Switzerland. 
Table 1. Summary Statistics \& Covariates of In-facility Delivery and Institutional ANC

\begin{tabular}{|c|c|c|c|c|c|c|}
\hline & \multicolumn{2}{|c|}{ Summary Statistics } & \multicolumn{2}{|c|}{$\begin{array}{l}\text { Association with Likelihood } \\
\text { of In-facility Delivery }\end{array}$} & \multicolumn{2}{|c|}{$\begin{array}{l}\text { Association with Likelihood of } \\
\text { Institutional ANC }\end{array}$} \\
\hline & (1) & $(2)$ & (3) & (4) & (5) & (6) \\
\hline & Mean & SD & Estimate & SE & Estimate & SE \\
\hline \multicolumn{7}{|l|}{ PANEL A: Individual level } \\
\hline Total Live Births & 2.748 & 1.922 & -0.803 & 0.023 & -0.580 & 0.026 \\
\hline Total Pregnancies & 2.982 & 2.051 & -0.853 & 0.024 & -0.668 & 0.028 \\
\hline Age at Survey & 27.055 & 6.716 & -2.485 & 0.074 & -2.907 & 0.116 \\
\hline Any Schooling & 0.493 & 0.500 & 0.284 & 0.008 & 0.266 & 0.007 \\
\hline Age at First Birth & 19.937 & 3.159 & 1.139 & 0.048 & 0.816 & 0.041 \\
\hline \multicolumn{7}{|l|}{ PANEL B: Household level } \\
\hline Toilet at Home & 0.280 & 0.449 & 0.178 & 0.011 & 0.150 & 0.009 \\
\hline Brick House & 0.469 & 0.499 & -0.194 & 0.009 & -0.112 & 0.008 \\
\hline Household has BPL Card & 0.351 & 0.477 & -0.049 & 0.007 & -0.017 & 0.006 \\
\hline Own House & 0.975 & 0.157 & -0.008 & 0.001 & -0.004 & 0.001 \\
\hline Own Bicycle & 0.488 & 0.500 & -0.001 & 0.009 & 0.033 & 0.008 \\
\hline Own Motor-vehicle & 0.141 & 0.348 & 0.136 & 0.005 & 0.087 & 0.004 \\
\hline Own Radio & 0.235 & 0.424 & 0.076 & 0.005 & 0.065 & 0.004 \\
\hline Own TV & 0.296 & 0.456 & 0.247 & 0.006 & 0.184 & 0.006 \\
\hline Own Agricultural Land & 0.635 & 0.481 & -0.002 & 0.008 & 0.006 & 0.007 \\
\hline Acres of Land & 1.962 & 4.079 & 0.638 & 0.057 & 0.390 & 0.048 \\
\hline Own Cattle & 0.584 & 0.493 & -0.029 & 0.008 & -0.026 & 0.006 \\
\hline Own Goats & 0.244 & 0.430 & -0.087 & 0.006 & -0.067 & 0.005 \\
\hline Own Poultry & 0.206 & 0.405 & -0.037 & 0.008 & 0.027 & 0.007 \\
\hline Wealth Quintile & 2.621 & 1.290 & 0.844 & 0.024 & 0.628 & 0.021 \\
\hline Houshold size & 6.781 & 3.291 & 0.222 & 0.034 & 0.242 & 0.035 \\
\hline
\end{tabular}

$\mathrm{N}=200671$; Sample is limited to those women reporting at least 1 pregnancy since 2004

Each number in Columns 3 and 5 is the coefficient from a univariate regression of in-facility delivery and institutional ANC on the corresponding covariate; Columns 4 and 6 report standard errors clustered at the district level 
Table 2. Placebo Effects of Roads on Care Variables during Pre-Program Period

\begin{tabular}{|c|c|c|c|c|c|}
\hline & (1) & (2) & (3) & (4) & (5) \\
\hline & $\begin{array}{l}\text { In-facility } \\
\text { Delivery }\end{array}$ & Institutional ANC & $\begin{array}{c}\text { Delivery } \\
\text { Complications }(=1)\end{array}$ & Tetanus Shot(=1) & $\begin{array}{l}\text { Received any IFA } \\
(=1)\end{array}$ \\
\hline $\begin{array}{l}\text { Roads Built by Year of } \\
\text { Delivery }\end{array}$ & $\begin{array}{l}-0.099 \\
(0.064)\end{array}$ & $\begin{array}{l}-0.005 \\
(0.086)\end{array}$ & $\begin{array}{l}-0.034 \\
(0.041)\end{array}$ & $\begin{array}{l}-0.030 \\
(0.065)\end{array}$ & $\begin{array}{l}-0.036 \\
(0.076)\end{array}$ \\
\hline Household Controls & Yes & Yes & Yes & Yes & Yes \\
\hline Individual controls & Yes & Yes & Yes & Yes & Yes \\
\hline District FE & Yes & Yes & Yes & Yes & Yes \\
\hline Observations & 64,257 & 64,257 & 64,257 & 64,257 & 64,257 \\
\hline R-squared & 0.108 & 0.078 & 0.001 & 0.049 & 0.038 \\
\hline Number of Districts & 551 & 551 & 551 & 551 & 551 \\
\hline Baseline Mean & 0.333 & 0.636 & 0.070 & 0.777 & 0.591 \\
\hline Baseline SD & 0.471 & 0.481 & 0.256 & 0.417 & 0.492 \\
\hline
\end{tabular}

Standard errors in parentheses. ${ }^{* * *}, * * *$ indicate significance at 1,5 and $10 \%$

Regressions include Year \& Month of Birth Fixed Effects; SEs are clustered at district level 
Table 3. Placebo Effects of Roads on Vaccination during Pre-Program Period

\begin{tabular}{|c|c|c|c|c|c|}
\hline & (1) & (2) & (3) & (4) & (5) \\
\hline & BCG & Measles & Hepatitis & Vitamin A & $\begin{array}{l}\text { Polio vaccine/drops } \\
\text { received at least once }\end{array}$ \\
\hline Roads Built by Year of & 0.014 & 0.037 & 0.032 & 0.100 & -0.073 \\
\hline Delivery & $(0.079)$ & $(0.133)$ & $(0.082)$ & $(0.113)$ & $(0.073)$ \\
\hline Household Controls & Yes & Yes & Yes & Yes & Yes \\
\hline Individual controls & Yes & Yes & Yes & Yes & Yes \\
\hline District FE & Yes & Yes & Yes & Yes & Yes \\
\hline Observations & 77,978 & 77,978 & 77,978 & 75,043 & 77,978 \\
\hline R-squared & 0.063 & 0.099 & 0.042 & 0.049 & 0.066 \\
\hline Number of Districts & 551 & 551 & 551 & 551 & 551 \\
\hline Baseline Mean & 0.427 & 0.288 & 0.075 & 0.303 & 0.444 \\
\hline Baseline SD & 0.495 & 0.453 & 0.263 & 0.460 & 0.497 \\
\hline
\end{tabular}

Standard errors in parentheses. ***, ** * indicate significance at 1, 5 and $10 \%$

Regressions include Year \& Month of Birth Fixed Effects; SEs are clustered at district level 


\begin{tabular}{lccc}
\hline \hline & $(1)$ & $(2)$ & $(3)$ \\
& $\begin{array}{c}\text { Pregnant in } \\
\text { Year X }\end{array}$ & $\begin{array}{c}\text { Child birth in } \\
\text { Year X }\end{array}$ & Spacing \\
\hline Roads Built in year X-1 & -0.014 & -0.015 & $0.224^{*}$ \\
& $(0.013)$ & $(0.013)$ & $(0.117)$ \\
Household Controls & Yes & Yes & Yes \\
District FE & Yes & Yes & Yes \\
Month FE & No & No & Yes \\
\hline Observations & $1,397,286$ & $1,397,286$ & 42,721 \\
R-squared & 0.253 & 0.259 & 0.319 \\
Baseline Mean & 0.0961 & 0.0921 & 0.00 \\
Baseline SD & 0.295 & 0.289 & 0.00 \\
Number of Districts & 558 & 558 & 557 \\
\hline \hline
\end{tabular}

Standard errors in parentheses. ${ }^{* * *}, * *, *$ indicate significance at 1,5 and $10 \%$

The mean of roads built by year X-1 is 0.0714

Regressions include year fixed effects and individual level controls

SEs are clustered by district 
Table 5. Impact of Road Construction on Access to Services

\begin{tabular}{|c|c|c|c|c|}
\hline & \multicolumn{3}{|c|}{ All } & \multirow{2}{*}{$\begin{array}{c}\text { Monsoon } \\
(4) \\
\text { In-facility } \\
\text { Delivery }\end{array}$} \\
\hline & $\begin{array}{c}\text { (1) } \\
\text { In-facility Delivery }\end{array}$ & $\begin{array}{c}\text { (2) } \\
\text { Institutional Ante- } \\
\text { natal Care } \\
\end{array}$ & $\begin{array}{c}\text { (3) } \\
\text { Transport Cost }\end{array}$ & \\
\hline \multicolumn{5}{|c|}{ PANEL A: All households with at least one pregnant woman } \\
\hline $\begin{array}{l}\text { Roads Built by Year of } \\
\text { Survey } \\
\text { Roads Built by Year of } \\
\text { Survey x Monsoon } \\
\text { Roads Built by Year of } \\
\text { Survey x Post Monsoon }\end{array}$ & $\begin{array}{c}0.190^{* * *} \\
(0.042)\end{array}$ & $\begin{array}{c}0.060^{*} \\
(0.031)\end{array}$ & $\begin{array}{l}-224.379 * \\
(117.945)\end{array}$ & $\begin{array}{c}0.134^{* * *} \\
(0.050) \\
0.107^{* * *} \\
(0.041) \\
0.179^{* * *} \\
(0.055)\end{array}$ \\
\hline $\begin{array}{l}\text { Household Controls } \\
\text { District FE }\end{array}$ & $\begin{array}{l}\text { Yes } \\
\text { Yes }\end{array}$ & $\begin{array}{l}\text { Yes } \\
\text { Yes }\end{array}$ & $\begin{array}{l}\text { Yes } \\
\text { Yes }\end{array}$ & $\begin{array}{l}\text { Yes } \\
\text { Yes }\end{array}$ \\
\hline Observations & 175,803 & 175,803 & 52,262 & 159,466 \\
\hline R-squared & 0.271 & 0.256 & 0.089 & 0.277 \\
\hline Baseline Mean & 0.322 & 0.610 & 316.9 & 0.322 \\
\hline Baseline SD & 0.467 & 0.488 & 690.6 & 0.467 \\
\hline Number of Districts & 558 & 558 & 558 & 558 \\
\hline \multicolumn{5}{|c|}{ PANEL B: All households with multiple pregnant women } \\
\hline $\begin{array}{l}\text { Roads Built by Year of } \\
\text { Delivery } \\
\text { Roads Built by Year of } \\
\text { Survey x Monsoon } \\
\text { Roads Built by Year of } \\
\text { Survey x Post Monsoon }\end{array}$ & $\begin{array}{l}0.240^{* *} \\
(0.117)\end{array}$ & $\begin{array}{c}0.067 \\
(0.101)\end{array}$ & $\begin{array}{c}-259.577 \\
(180.659)\end{array}$ & $\begin{array}{c}0.120 \\
(0.138) \\
0.218^{* *} \\
(0.103) \\
0.028 \\
(0.139)\end{array}$ \\
\hline Households FE & Yes & Yes & Yes & Yes \\
\hline Observations & 19,172 & 19,172 & 6,554 & 17,348 \\
\hline R-squared & 0.692 & 0.713 & 0.844 & 0.719 \\
\hline Baseline Mean & 0.403 & 0.652 & 272.2 & 0.381 \\
\hline Baseline SD & 0.491 & 0.476 & 277 & 0.486 \\
\hline Number of Households & 9424 & 9424 & 4679 & 9275 \\
\hline
\end{tabular}

Standard errors in parentheses. ${ }^{* * *}, * *, *$ indicate significance at 1,5 and $10 \%$

The mean of roads built by year of delivery is 0.0714

Regressions include year \& month of birth fixed effects and individual level controls. SEs are clustered by district Regressions using monsoon as dependent variable do not include births in the year 2008 as some households were interviewed before the monsoon 
Table 6. Impact of road construction on deliveries on the way to the hospital

\begin{tabular}{lc}
\hline \hline & On the way to the hospital \\
\hline Roads Built by Year of & $-0.007^{* *}$ \\
Delivery & $(0.003)$ \\
& \\
\hline Observations & 175,803 \\
R-squared & 0.005 \\
Baseline Mean & 0.00420 \\
Baseline SD & 0.0647 \\
Number of Districts & 558 \\
\hline \hline
\end{tabular}

Standard errors in parentheses. ${ }^{* * *},{ }^{* *}, *$ indicate significance at 1,5 and $10 \%$

The mean of roads built by year of delivery is 0.0714

Regressions include District, Year \& Month of Birth FE; SEs

are clustered at district level

Include household and individual level controls 
Table 7. Impact of Road Construction on Quality of Care

\begin{tabular}{|c|c|c|c|c|c|c|c|c|}
\hline & \multicolumn{5}{|c|}{ ANC Quality } & \multicolumn{3}{|c|}{ Delivery Quality } \\
\hline & (1) & $(2)$ & (3) & (4) & (5) & (6) & (7) & (8) \\
\hline & $\begin{array}{l}\text { Any anc health } \\
\text { measures }(=1)\end{array}$ & $\begin{array}{l}\text { All ANC health } \\
\text { measures }\end{array}$ & Any advice $(=1)$ & $\begin{array}{l}\text { Tetanus } \\
\text { Shot }(=1)\end{array}$ & $\begin{array}{l}\text { Received any } \\
\text { IFA }(=1)\end{array}$ & $\begin{array}{c}\text { Delivery } \\
\text { Complications }(=1)\end{array}$ & $\begin{array}{l}\text { Timely Checkup } \\
\text { (Either mother or } \\
\text { child) }\end{array}$ & $\begin{array}{c}\text { Timely Checkup } \\
\text { (Both) }\end{array}$ \\
\hline \multicolumn{9}{|c|}{ PANEL A: All households with at least one pregnant woman } \\
\hline $\begin{array}{l}\text { Roads Built by Year } \\
\text { of Delivery }\end{array}$ & $\begin{array}{c}0.006 \\
(0.028)\end{array}$ & $\begin{array}{l}-0.127 \\
(0.136)\end{array}$ & $\begin{array}{c}0.049 * \\
(0.029)\end{array}$ & $\begin{array}{c}0.057^{*} \\
(0.031)\end{array}$ & $\begin{array}{l}0.052^{* *} \\
(0.026)\end{array}$ & $\begin{array}{c}-0.041^{* *} \\
(0.020)\end{array}$ & $\begin{array}{l}0.142^{* * *} \\
(0.034)\end{array}$ & $\begin{array}{l}0.108^{* * *} \\
(0.031)\end{array}$ \\
\hline Household Controls & Yes & Yes & Yes & Yes & Yes & Yes & Yes & Yes \\
\hline District FE & Yes & Yes & Yes & Yes & Yes & Yes & Yes & Yes \\
\hline Observations & 175,803 & 175,803 & 175,803 & 175,803 & 175,803 & 175,803 & 175,803 & 175,803 \\
\hline R-squared & 0.316 & 0.478 & 0.251 & 0.226 & 0.116 & 0.063 & 0.242 & 0.240 \\
\hline Baseline Mean & 0.546 & 2.469 & 0.569 & 0.641 & 0.864 & 0.127 & 0.409 & 0.331 \\
\hline Baseline SD & 0.498 & 2.857 & 0.495 & 0.480 & 0.343 & 0.333 & 0.492 & 0.470 \\
\hline Number of Districts & 558 & 558 & 558 & 558 & 558 & 558 & 558 & 558 \\
\hline \multicolumn{9}{|c|}{ PANEL B: All households with multiple pregnant women } \\
\hline Roads Built by Year & 0.044 & -0.028 & 0.047 & 0.059 & 0.119 & -0.075 & 0.145 & 0.079 \\
\hline of Delivery & $(0.098)$ & $(0.480)$ & $(0.101)$ & $(0.095)$ & $(0.086)$ & $(0.074)$ & $(0.111)$ & $(0.098)$ \\
\hline Households FE & Yes & Yes & Yes & Yes & Yes & Yes & Yes & Yes \\
\hline Observations & 19,172 & 19,172 & 19,172 & 19,172 & 19,172 & 19,172 & 19,172 & 19,172 \\
\hline R-squared & 0.722 & 0.792 & 0.711 & 0.708 & 0.623 & 0.607 & 0.699 & 0.706 \\
\hline Baseline Mean & 0.579 & 2.608 & 0.607 & 0.706 & 0.810 & 0.125 & 0.453 & 0.365 \\
\hline Baseline SD & 0.494 & 2.855 & 0.489 & 0.456 & 0.392 & 0.331 & 0.498 & 0.481 \\
\hline Number of Households & 9424 & 9424 & 9424 & 9424 & 9424 & 9424 & 9424 & 9424 \\
\hline
\end{tabular}

Standard errors in parentheses. ${ }^{* * *}, * * *$ indicate significance at 1,5 and $10 \%$

The mean of roads built by year of delivery is 0.0714

Regressions include year \& month of birth fixed effects and individual level controls

SEs are clustered at district level 
Table 8. Impact of Road Construction on Children's Immunization

\begin{tabular}{|c|c|c|c|c|c|c|}
\hline & $\begin{array}{c}(1) \\
\text { BCG }\end{array}$ & $\begin{array}{l}(2) \\
\text { DPT }\end{array}$ & $\begin{array}{c}(3) \\
\text { Measles }\end{array}$ & $\begin{array}{c}\text { (4) } \\
\text { Vitamin A }\end{array}$ & $\begin{array}{c}\text { (5) } \\
\text { Hepatitis }\end{array}$ & $\begin{array}{l}\text { (6) } \\
\text { Polio vaccine/drops } \\
\text { received at least once }\end{array}$ \\
\hline \multicolumn{7}{|c|}{ PANEL A: All mothers with at least one child born in sample period } \\
\hline $\begin{array}{l}\text { Roads Built by Year of } \\
\text { Delivery }\end{array}$ & $\begin{array}{c}0.151^{* * *} \\
(0.044)\end{array}$ & $\begin{array}{c}0.142^{* * *} \\
(0.048)\end{array}$ & $\begin{array}{c}0.261^{* * *} \\
(0.061)\end{array}$ & $\begin{array}{c}0.188^{* * *} \\
(0.065)\end{array}$ & $\begin{array}{c}0.207^{* * *} \\
(0.034)\end{array}$ & $\begin{array}{c}0.036 \\
(0.031)\end{array}$ \\
\hline $\begin{array}{l}\text { Household Controls } \\
\text { Individual controls } \\
\text { District Fixed Effects }\end{array}$ & $\begin{array}{l}\text { Yes } \\
\text { Yes } \\
\text { Yes }\end{array}$ & $\begin{array}{l}\text { Yes } \\
\text { Yes } \\
\text { Yes }\end{array}$ & $\begin{array}{l}\text { Yes } \\
\text { Yes } \\
\text { Yes }\end{array}$ & $\begin{array}{l}\text { Yes } \\
\text { Yes } \\
\text { Yes }\end{array}$ & $\begin{array}{l}\text { Yes } \\
\text { Yes } \\
\text { Yes }\end{array}$ & $\begin{array}{l}\text { Yes } \\
\text { Yes } \\
\text { Yes }\end{array}$ \\
\hline $\begin{array}{l}\text { Observations } \\
\text { R-squared } \\
\text { Baseline Mean } \\
\text { Baseline SD } \\
\text { Number of Districts }\end{array}$ & $\begin{array}{c}211,636 \\
0.155 \\
0.782 \\
0.413 \\
558\end{array}$ & $\begin{array}{c}211,636 \\
0.209 \\
0.731 \\
0.444 \\
558\end{array}$ & $\begin{array}{c}211,636 \\
0.312 \\
0.644 \\
0.479 \\
558\end{array}$ & $\begin{array}{c}211,636 \\
0.282 \\
0.561 \\
0.496 \\
558\end{array}$ & $\begin{array}{c}211,636 \\
0.282 \\
0.243 \\
0.429 \\
558\end{array}$ & $\begin{array}{c}211,636 \\
0.146 \\
0.909 \\
0.288 \\
558\end{array}$ \\
\hline \multicolumn{7}{|c|}{ PANEL B: All mothers with more than one child born in sample period } \\
\hline $\begin{array}{l}\text { Roads Built by Year of } \\
\text { Delivery }\end{array}$ & $\begin{array}{c}0.148^{* * *} \\
(0.055)\end{array}$ & $\begin{array}{c}0.159^{* * *} \\
(0.060)\end{array}$ & $\begin{array}{c}0.214^{* * *} \\
(0.074)\end{array}$ & $\begin{array}{c}0.149 * \\
(0.077)\end{array}$ & $\begin{array}{c}0.225^{* * *} \\
(0.036)\end{array}$ & $\begin{array}{c}0.003 \\
(0.039)\end{array}$ \\
\hline Individual Fixed Effects & Yes & Yes & Yes & Yes & Yes & Yes \\
\hline Observations & 84,200 & 84,200 & 84,200 & 84,200 & 84,200 & 84,200 \\
\hline R-squared & 0.749 & 0.739 & 0.747 & 0.764 & 0.798 & 0.752 \\
\hline Baseline Mean & 0.759 & 0.706 & 0.614 & 0.524 & 0.216 & 0.897 \\
\hline Baseline SD & 0.428 & 0.456 & 0.487 & 0.499 & 0.412 & 0.304 \\
\hline Number of Mothers & 42100 & 42100 & 42100 & 42100 & 42100 & 42100 \\
\hline
\end{tabular}

Standard errors in parentheses. ${ }^{* * *}, * * *$ indicate significance at 1,5 and $10 \%$

The mean of roads built by year of delivery is 0.0714

All regressions include year \& month of birth fixed effects, and those in Panel B additionally include mother fixed effects; SEs are clustered at district level 
Table 9. Changes in Providers

\begin{tabular}{|c|c|c|c|c|}
\hline & \multicolumn{2}{|c|}{ Unconditional } & \multicolumn{2}{|c|}{ Conditional } \\
\hline & (1) & (2) & (3) & (4) \\
\hline & $\begin{array}{l}\text { Private Hospital } \\
\text { Delivery }\end{array}$ & $\begin{array}{c}\text { Pvt. Institutional Ante- } \\
\text { natal Care }\end{array}$ & $\begin{array}{l}\text { Private Hospital } \\
\text { Delivery }\end{array}$ & $\begin{array}{l}\text { Pvt. Institutional } \\
\text { Ante-natal Care }\end{array}$ \\
\hline \multirow{2}{*}{ Roads Built by Year of Delivery } & $-0.083^{* * *}$ & $-0.049^{* * *}$ & $-0.304^{* * *}$ & $-0.098^{* * *}$ \\
\hline & $(0.016)$ & $(0.019)$ & $(0.066)$ & $(0.031)$ \\
\hline$\overline{\text { Observations }}$ & 175,803 & 175,803 & 63,217 & 108,292 \\
\hline R-squared & 0.217 & 0.219 & 0.302 & 0.244 \\
\hline Baseline Mean & 0.135 & 0.214 & 0.419 & 0.351 \\
\hline Baseline SD & 0.342 & 0.410 & 0.493 & 0.477 \\
\hline Number of Districts & 558 & 558 & 558 & 558 \\
\hline
\end{tabular}

Sample is limited to those women reporting at least 1 live/still birth since 2004

Standard errors in parentheses. ${ }^{* * *}, * *, *$ indicate significance at 1,5 and $10 \%$

The mean of roads built by year of delivery is 0.0714

Regressions include District, Year \& Month of Birth Fixed Effects; SEs are clustered at district level

Include household and individual level controls 


\begin{tabular}{|c|c|c|c|c|c|c|}
\hline & $\begin{array}{c}\text { (1) } \\
\text { Public } \\
\text { Hospital }\end{array}$ & $\begin{array}{c}\text { (2) } \\
\text { Urban } \\
\text { Health } \\
\text { Centres }\end{array}$ & $\begin{array}{c}(3) \\
\text { Community } \\
\text { Health } \\
\text { Centres } \\
\text { (CHCs) } \\
\end{array}$ & $\begin{array}{c}(4) \\
\text { Primary } \\
\text { Health } \\
\text { Centres } \\
\text { (PHCs) }\end{array}$ & $\begin{array}{l}\text { Sub centres } \\
\text { (SCs) }\end{array}$ & $\begin{array}{l}\text { All private } \\
\text { facilities }\end{array}$ \\
\hline \multicolumn{7}{|c|}{ PANEL A: All mothers with at least one child born in sample period } \\
\hline Roads Built by Year of Delivery & $\begin{array}{c}0.124^{* * *} \\
(0.022)\end{array}$ & $\begin{array}{c}0.001 \\
(0.003)\end{array}$ & $\begin{array}{c}0.018 \\
(0.016)\end{array}$ & $\begin{array}{c}0.123^{* * *} \\
(0.023)\end{array}$ & $\begin{array}{l}0.014^{* *} \\
(0.006)\end{array}$ & $\begin{array}{c}-0.083^{* * *} \\
(0.016)\end{array}$ \\
\hline Household Controls & Yes & Yes & Yes & Yes & Yes & Yes \\
\hline District FE & Yes & Yes & Yes & Yes & Yes & Yes \\
\hline Observations & 175,803 & 175,803 & 175,803 & 175,803 & 175,803 & 175,803 \\
\hline R-squared & 0.140 & 0.023 & 0.064 & 0.049 & 0.017 & 0.217 \\
\hline Baseline Mean & 0.105 & 0.00245 & 0.0349 & 0.0341 & 0.00540 & 0.135 \\
\hline Baseline SD & 0.306 & 0.0494 & 0.184 & 0.181 & 0.0733 & 0.342 \\
\hline Number of Districts & 558 & 558 & 558 & 558 & 558 & 558 \\
\hline \multicolumn{7}{|c|}{ PANEL B: All households with multiple pregnant women } \\
\hline Roads Built by Year of Delivery & $\begin{array}{l}0.156^{* *} \\
(0.074)\end{array}$ & $\begin{array}{l}-0.002 \\
(0.010)\end{array}$ & $\begin{array}{c}0.012 \\
(0.044)\end{array}$ & $\begin{array}{c}0.183^{* * *} \\
(0.069)\end{array}$ & $\begin{array}{l}0.063^{*} \\
(0.036)\end{array}$ & $\begin{array}{l}-0.152^{*} \\
(0.080)\end{array}$ \\
\hline Household FE & Yes & Yes & Yes & Yes & Yes & Yes \\
\hline Observations & 19,172 & 19,172 & 19,172 & 19,172 & 19,172 & 19,172 \\
\hline R-squared & 0.659 & 0.544 & 0.641 & 0.618 & 0.610 & 0.686 \\
\hline Baseline Mean & 0.0937 & 0.00180 & 0.0442 & 0.0441 & 0.00635 & 0.181 \\
\hline Baseline SD & 0.291 & 0.0424 & 0.206 & 0.205 & 0.0794 & 0.385 \\
\hline Number of Households & 9424 & 9424 & 9424 & 9424 & 9424 & 9424 \\
\hline
\end{tabular}

Standard errors in parentheses. ***, ** * indicate significance at 1, 5 and 10\%

The mean of roads built by year of delivery is 0.0714

Regressions include District, Year \& Month of Birth Fixed Effects; SEs are clustered at district level 
Table 11. Impact of road construction on choice of locations for ante-natal care

\begin{tabular}{|c|c|c|c|c|c|c|}
\hline & $\begin{array}{c}\text { (1) } \\
\text { Public } \\
\text { Hospital }\end{array}$ & $\begin{array}{c}\text { (2) } \\
\text { Urban } \\
\text { Health } \\
\text { Centres }\end{array}$ & $\begin{array}{c}(3) \\
\text { Community } \\
\text { Health } \\
\text { Centres } \\
\text { (CHCs) } \\
\end{array}$ & $\begin{array}{c}\text { (4) } \\
\text { Primary } \\
\text { Health } \\
\text { Centres } \\
\text { (PHCs) } \\
\end{array}$ & $\begin{array}{c}\text { (5) } \\
\text { Sub centres } \\
\text { (SCs) }\end{array}$ & $\begin{array}{l}\text { All private } \\
\text { facilities }\end{array}$ \\
\hline \multicolumn{7}{|c|}{ PANEL A: All mothers with at least one child born in sample period } \\
\hline Roads Built by Year of Delivery & $\begin{array}{c}-0.000 \\
(0.021)\end{array}$ & $\begin{array}{c}-0.004 \\
(0.004)\end{array}$ & $\begin{array}{c}0.009 \\
(0.012)\end{array}$ & $\begin{array}{c}0.021 \\
(0.018)\end{array}$ & $\begin{array}{c}0.077^{* * *} \\
(0.018)\end{array}$ & $\begin{array}{c}-0.049^{* * *} \\
(0.019)\end{array}$ \\
\hline Household Controls & Yes & Yes & Yes & Yes & Yes & Yes \\
\hline District FE & Yes & Yes & Yes & Yes & Yes & Yes \\
\hline Observations & 175,803 & 175,803 & 175,803 & 175,803 & 175,803 & 175,803 \\
\hline R-squared & 0.140 & 0.016 & 0.057 & 0.058 & 0.224 & 0.219 \\
\hline Baseline Mean & 0.116 & 0.00545 & 0.0604 & 0.0993 & 0.102 & 0.214 \\
\hline Baseline SD & 0.320 & 0.0736 & 0.238 & 0.299 & 0.303 & 0.410 \\
\hline Number of Districts & 558 & 558 & 558 & 558 & 558 & 558 \\
\hline \multicolumn{7}{|c|}{ PANEL B: All households with multiple pregnant women } \\
\hline Roads Built by Year of Delivery & $\begin{array}{l}0.129 * * \\
(0.063)\end{array}$ & $\begin{array}{c}-0.007 \\
(0.020)\end{array}$ & $\begin{array}{c}-0.044 \\
(0.047)\end{array}$ & $\begin{array}{c}-0.008 \\
(0.068)\end{array}$ & $\begin{array}{c}0.064 \\
(0.065)\end{array}$ & $\begin{array}{c}-0.128 \\
(0.091)\end{array}$ \\
\hline Household FE & Yes & Yes & Yes & Yes & Yes & Yes \\
\hline Observations & 19,172 & 19,172 & 19,172 & 19,172 & 19,172 & 19,172 \\
\hline R-squared & 0.671 & 0.553 & 0.647 & 0.656 & 0.695 & 0.685 \\
\hline Baseline Mean & 0.103 & 0.00508 & 0.0561 & 0.0992 & 0.0875 & 0.262 \\
\hline Baseline SD & 0.304 & 0.0711 & 0.230 & 0.299 & 0.283 & 0.440 \\
\hline Number of Households & 9424 & 9424 & 9424 & 9424 & 9424 & 9424 \\
\hline
\end{tabular}

Standard errors in parentheses. ${ }^{* * *},{ }^{* *}, *$ indicate significance at 1,5 and $10 \%$

The mean of roads built by year of delivery is 0.0714

Regressions include District, Year \& Month of Birth Fixed Effects; SEs are clustered at district level 
Table 12. Changes in Treatment Seeking for Other Diseases

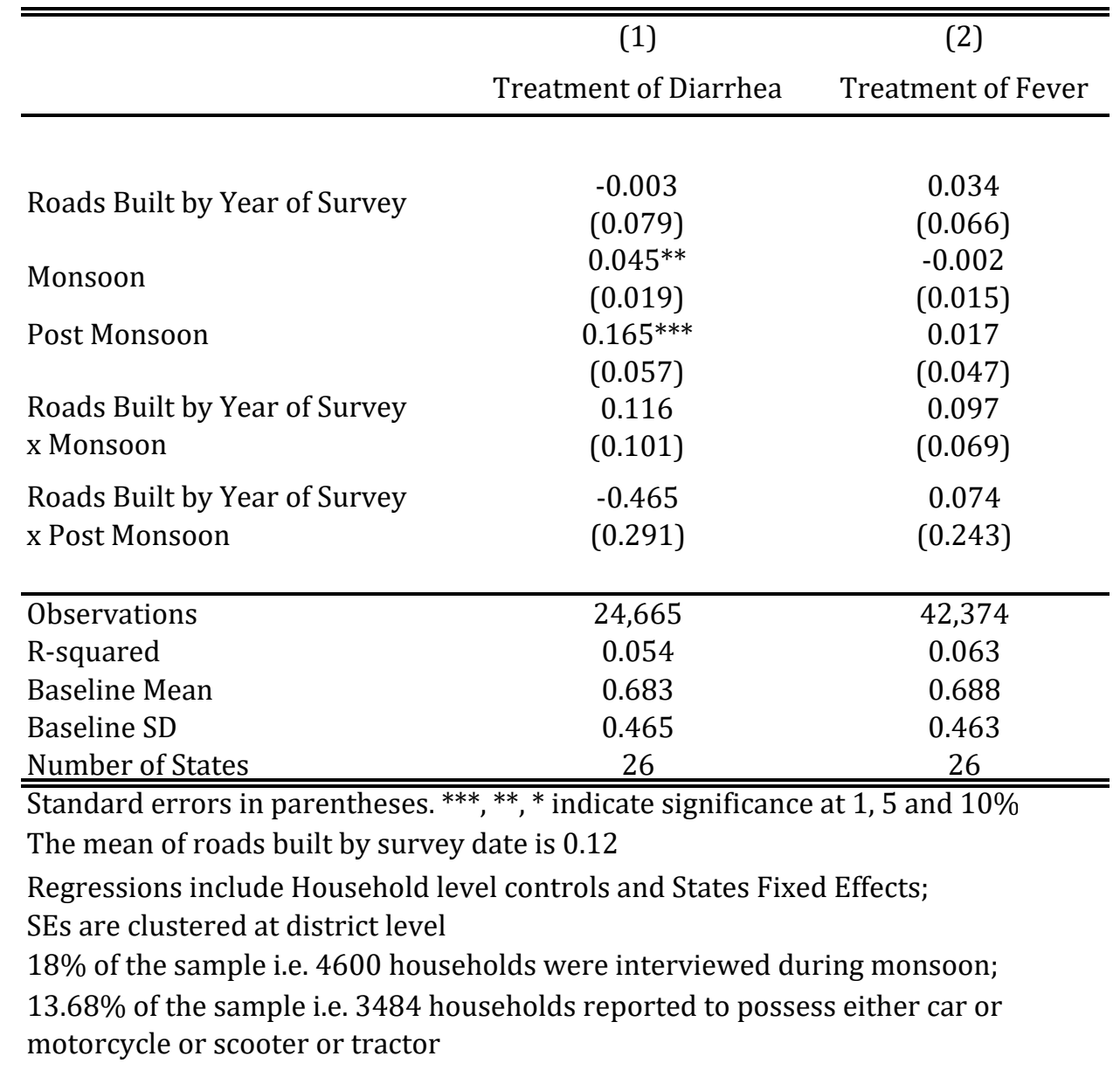


Table 13. Impact of road construction on JSY beneficiaries

\begin{tabular}{lc}
\hline \hline & $\begin{array}{c}\text { Received JSY financial } \\
\text { assistance }\end{array}$ \\
\hline Roads Built by Year of & $0.343^{* * *}$ \\
Delivery & $(0.047)$ \\
& \\
\hline Observations & 170,574 \\
R-squared & 0.127 \\
Baseline Mean & 0.0431 \\
Baseline SD & 0.203 \\
Number of Districts & 558 \\
\hline \hline
\end{tabular}

Standard errors in parentheses. ${ }^{* * *}, * *, *$ indicate significance at 1,5 and $10 \%$

The mean of roads built by year of delivery is 0.0714

Regressions include District, Year \& Month of Birth FE; SEs

are clustered at district level

Include household and individual level controls 
Web Appendix

The Long Road to Health: Healthcare Utilization Impacts of a Road Pavement Policy in Rural India

Shilpa Aggarwal 


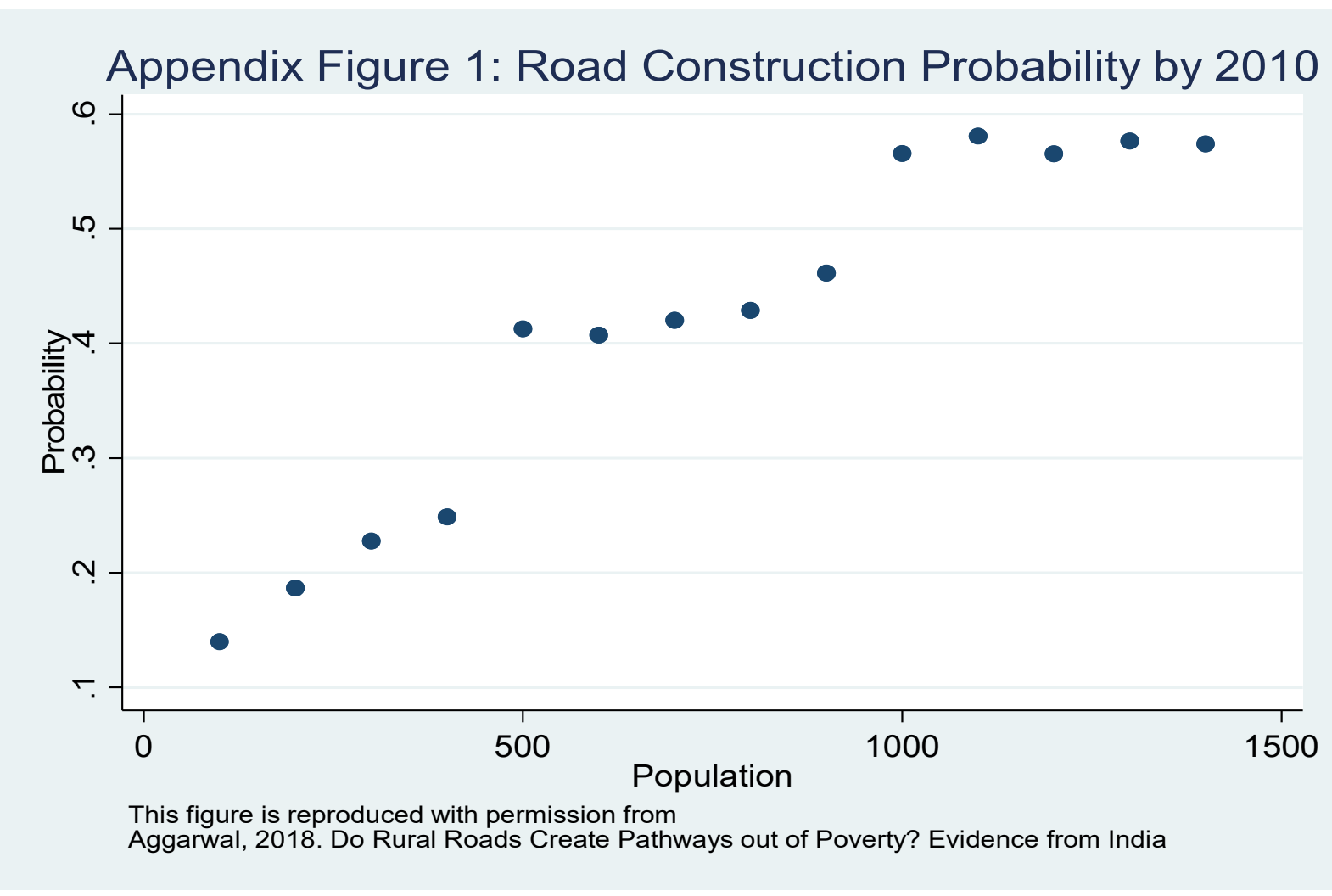


Appendix Table A1. Does a PMGSY Road Predict other Public Goods?

\begin{tabular}{cccccccc}
\hline & $\begin{array}{c}\text { Elementary } \\
\text { School }\end{array}$ & $\begin{array}{c}\text { High } \\
\text { School }\end{array}$ & $\begin{array}{c}\text { Primary } \\
\text { Health } \\
\text { Center }\end{array}$ & Post Office & Bus Station & $\begin{array}{c}\text { Railway } \\
\text { Station }\end{array}$ & Bank \\
\cline { 2 - 8 } & 0.0027 & 0.0038 & 0.0012 & $0.0016^{*}$ & $0.0285^{* * *}$ & -0.0007 & -0.0013 \\
PMGSY beneficiary & $(0.005)$ & $(0.003)$ & $(0.001)$ & $(0.001)$ & $(0.005)$ & $(0.0004)$ & $(0.001)$ \\
Village & & & & & & & \\
& & & & & & \\
Observations & 175,708 & 175,708 & 175,708 & 175,708 & 175,708 & 175,708 & 175,708 \\
R-Squared & 0.013 & 0.005 & 0.001 & 0.001 & 0.005 & 0 & 0.001 \\
\hline
\end{tabular}

Standard errors in parentheses, clustered at the state level.

$* * *, * *, *$ indicate significance at 1,5 and $10 \%$

All specifications have district fixed effects

All specifications control for village population category at baseline, i.e., 2001 census

Source: Aggarwal (2018), Do Rural Roads Create Pathways out of Poverty? Evidence from India 
Appendix Table A2. Cross-tabulation of IANC and in-facility delivery

\begin{tabular}{c|cc|c}
\hline \hline \multirow{2}{*}{ Institutional ANC } & \multicolumn{2}{|c}{} \\
\cline { 2 - 3 } & \multicolumn{2}{|c}{ In-facility Delivery } & \multirow{2}{*}{ TOTAL } \\
\hline Yes & Yes & No & 219,884 \\
No & 109,808 & 110,076 & 181,460 \\
\hline \hline TOTAL & 18,952 & 162,508 & 401,344
\end{tabular}


Appendix Table A3. Summary Statistics of Different Covariates

\begin{tabular}{|c|c|c|c|c|}
\hline & \multicolumn{2}{|c|}{$\begin{array}{l}\text { All households with at least one } \\
\text { pregnant woman }\end{array}$} & \multicolumn{2}{|c|}{$\begin{array}{l}\text { Association with Likelihood of } \\
\text { In-facility Delivery }\end{array}$} \\
\hline & Mean & SD & Mean & SD \\
\hline \multicolumn{5}{|l|}{ PANEL A: Individual level } \\
\hline Total Live Births & 2.748 & 1.922 & 2.325 & 1.661 \\
\hline Total Pregnancies & 2.982 & 2.051 & 2.582 & 1.813 \\
\hline Age at Survey & 27.055 & 6.716 & 24.803 & 5.278 \\
\hline Any Schooling & 0.493 & 0.500 & 0.563 & 0.496 \\
\hline Age at First Birth & 19.937 & 3.159 & 19.862 & 2.97 \\
\hline \multicolumn{5}{|l|}{ PANEL B: Household level } \\
\hline Toilet at Home & 0.280 & 0.449 & 0.298 & 0.458 \\
\hline Brick House & 0.469 & 0.499 & 0.326 & 0.469 \\
\hline Household has BPL Card & 0.351 & 0.477 & 0.324 & 0.468 \\
\hline Own House & 0.975 & 0.157 & 0.99 & 0.098 \\
\hline Own Bicycle & 0.488 & 0.500 & 0.642 & 0.479 \\
\hline $\begin{array}{l}\text { Own Motorcycle or car or } \\
\text { tractor }\end{array}$ & 0.141 & 0.348 & 0.287 & 0.452 \\
\hline Own Radio & 0.235 & 0.424 & 0.309 & 0.462 \\
\hline Own TV & 0.296 & 0.456 & 0.425 & 0.494 \\
\hline Own Agricultural Land & 0.635 & 0.481 & 0.773 & 0.419 \\
\hline Acres of Land & 1.962 & 4.079 & 3.484 & 5.775 \\
\hline Own Cattle & 0.584 & 0.493 & 0.776 & 0.417 \\
\hline Own Goats & 0.244 & 0.430 & 0.282 & 0.450 \\
\hline Own Poultry & 0.206 & 0.405 & 0.167 & 0.373 \\
\hline Wealth Quintile & 2.621 & 1.290 & 11.911 & 4.122 \\
\hline Houshold size & 6.781 & 3.291 & 3.132 & 1.285 \\
\hline
\end{tabular}

N = 200671 for households with at least one pregnant women

$\mathrm{N}=19725$ for households with multiple pregnant women 
Appendix Table A4. Heterogeneity by PMGSY Implementation Quality

\begin{tabular}{|c|c|c|c|}
\hline & $\begin{array}{c}\text { (1) } \\
\text { In-facility Delivery }\end{array}$ & $\begin{array}{c}(2) \\
\text { Institutional Ante- } \\
\text { natal Care }\end{array}$ & $\begin{array}{c}\text { (3) } \\
\text { Transport Cost }\end{array}$ \\
\hline Roads Built by Year of Delivery & $\begin{array}{c}0.055 \\
(0.045)\end{array}$ & $\begin{array}{c}0.038 \\
(0.035)\end{array}$ & $\begin{array}{l}-243.235^{*} \\
(137.373)\end{array}$ \\
\hline Roads Built by Year of Delivery X & $0.640^{* * *}$ & $0.104^{*}$ & 96.931 \\
\hline Good implementing States & $(0.143)$ & $(0.057)$ & $(192.424)$ \\
\hline Household Controls & Yes & Yes & Yes \\
\hline District FE & Yes & Yes & Yes \\
\hline Observations & 175,803 & 175,803 & 52,262 \\
\hline R-squared & 0.272 & 0.256 & 0.089 \\
\hline Baseline Mean & 0.322 & 0.610 & 316.9 \\
\hline Baseline SD & 0.467 & 0.488 & 690.6 \\
\hline Number of Districts & 558 & 558 & 558 \\
\hline
\end{tabular}

Standard errors in parentheses. ${ }^{* * *},{ }^{* *}, *$ indicate significance at 1,5 and $10 \%$

The mean of roads built by year of delivery is 0.0714

Regressions include year \& month of birth fixed effects and individual level controls.

SEs are clustered by district

The difference in mean road connectivity between good and bad implementers is 0.018 